Pedro Henrique Hernandes Job

Validação do software Vectra Face Sculptor para avaliação de alteração volumétrica na análise do efeito antiedematoso do laser sistêmico ou pontual em área de rebordo fissurado enxertado com osso autógeno 



\title{
Validação do software Vectra Face Sculptor para avaliação de alteração volumétrica na análise do efeito antiedematoso do laser sistêmico ou pontual em área de rebordo fissurado enxertado com osso autógeno
}

\author{
Dissertação apresentada a Faculdade de \\ Odontologia de Bauru da Universidade de \\ São Paulo para obtenção do título de Mestre \\ em Ciências no Programa de Ciências \\ Odontológicas Aplicadas, na área de \\ concentração Reabilitação Oral. \\ Orientadora: Profa ${ }^{\text {. Dr }}{ }^{\mathrm{a}}$ Ana Lucia Pompéia \\ Fraga De Almeida
}


Job, Pedro Henrique Hernandes

Validação do software Vectra Face Sculptor para avaliação de alteração volumétrica na análise do efeito antiedematoso do laser sistêmico ou pontual em área de rebordo fissurado enxertado com osso autógeno/ Pedro Henrique Hernandes Job. -- Bauru, 2021.

91 p. : il. ; $31 \mathrm{~cm}$.

Dissertação (mestrado) -- Faculdade de Odontologia de Bauru, Universidade de São Paulo, ano de defesa.

Orientador: Profa. Dra. Ana Lucia Pompeia Fraga De Almeida

Autorizo, exclusivamente para fins acadêmicos e científicos, a reprodução total ou parcial desta dissertação/tese, por processos fotocopiadores e outros meios eletrônicos.

Assinatura:

Data:

Comitê de Ética da HRAC-USP

Protocolo $\mathrm{n}^{\mathrm{0}}$ : 3.046 .783

Data: $29 / 11 / 2018$ 
ERRATA 

FOLHA DE APROVAÇÃO 



\section{DEDICATÓRIA}

Dedico esse trabalho à minha família que sempre me apoiou, em especial meu pai Aldo pelo exemplo profissional na docência, minha mãe Ângela pelas orientações e meu irmão José pelo exemplo em como ser um profissional de saúde ético e competente.

Dedico também à minha namorada Ana, sua paciência, suas orientações, seu carinho foram fundamentais para essa etapa de minha vida. 



\section{AGRADECIMENTOS}

Agradeço meus pais, Aldo e Ângela por todo esforço e sacrifício feito em prol de minha educação, por serem exemplos de moral e por me fazerem desde cedo entender a importância do estudo, sem dúvida esse trabalho é resultado do empenho de vocês. Agradeço também por sempre atenderem minhas ligações quando eu mais precisei de ajuda e sempre as responder com carinho e orientações para me ajudar. E por fim agradeço por entenderem minha ausência de casa e por sempre me receberem com amor e carinho em meus retornos durante os feriados.

Agradeço a minha namorada Ana, por todo carinho, amor, dedicação e paciência. Seu apoio durante as dificuldades foi fundamental para eu conseguir seguir em frente.

Agradeço o Hospital de Reabilitação de Anomalias Craniofaciais por contribuir para minha formação. Em especial ao setor de cirurgia do HRAC que foi muito prestativo durante a realização desse trabalho.

Agradeço à Faculdade de Odontologia de Bauru e aos funcionários e professores do departamento de prótese por contribuir para minha formação. Em especial aos professores José Rubo e Estevam Bonfante, suas críticas foram essenciais para meu aprendizado.

Agradeço imensamente aos meus professores Luis Esper e Patrick Alves, carregarei para sempre seus ensinamentos, tenho certeza de que não seria o profissional que sou sem a ajuda e o exemplo de vocês. Espero um dia ter ao menos um aluno tenha por mim a admiração e carinho que tenho por vocês.

Agradeço imensamente à minha orientadora Profa. ${ }^{a} r^{\mathrm{a}}$. Ana Lucia Pompeia Fraga de Almeida, por me aceitar como orientado e por ser um exemplo de profissional a ser seguido.

O presente trabalho foi realizado com o apoio da Coordenação de Aperfeiçoamento de Pessoal de Nivel Superior - Brasil (CAPES) - Código de Financiamento 001. Muito obrigado. 



\section{RESUMO}

As fissuras labiopalatinas estão entre as malformações de face mais comuns, acarretam implicações estéticas e funcionais representando um desafio reabilitador e mobilizando um extenso protocolo de tratamento. Este protocolo apresenta diversos procedimentos cirúrgicos realizados desde os primeiros meses de vida do paciente até a idade adulta. Devido ao extenso protocolo cirúrgico o paciente portador de fissura labiopalatina é submetido a diversões tratamentos que promovem grande morbidade como dor e edema. Uma cirurgia fundamental no protocolo reabilitador é o enxerto ósseo na região da fissura, cirurgia essa que promove grande morbidade ao paciente como desconforto ao se alimentar, respirar e locomover devido ao desenvolvimento de edema e dor no período pós-operatório. O laser de baixa intensidade tem sido utilizado com sucesso na regeneração óssea em estudos laboratoriais, assim como diversos estudos apontam para a relação entre seu uso e a redução do edema. O objetivo deste estudo foi validar a utilização do software Vectra Face Sculptor para avaliação de alteração volumétrica, assim como avaliar o efeito do laser sistêmico ou pontual em área de rebordo alveolar fissurado enxertado com osso autógeno sobre o edema pós-operatório.

A validação da utilização da análise estereofotogramétrica foi feita a partir da medição da alteração volumétrica em imagens digitais com dimensões conhecidas e avaliação da precisão da reprodução das imagens feitas com o equipamento Vectra H1. Para avaliação do efeito do laser de baixa intensidade foi coletada amostra de 18 indivíduos submetidos a cirurgia de regeneração óssea que foi dividida em 3 grupos $(n=6)$ : grupo 1 (controle) - enxerto ósseo sem aplicação de laser; grupo 2 (LBIL-6J) enxerto ósseo com aplicação de laser pontual; grupo 3 (ILIB) - enxerto ósseo com aplicação de laser sistêmico. O laser utilizado nos Grupos 2 e 3 foi no comprimento de onda no espectro infravermelho $(880 \mathrm{~nm} \pm 10 \mathrm{~nm})$ e do vermelho $(660 \mathrm{~nm} \pm 10 \mathrm{~nm})$ respectivamente, com potência útil emissor: $100 \mathrm{~mW} \pm 20 \%$, nos períodos T1L - pósoperatório imediato, T2L - 24 horas pós-operatório. As tomadas fotográficas foram realizadas nos seguintes tempos: TOF - 24 horas no pré-operatório, T1F - 24 horas pós-operatório e T2F -48 horas pós-operatório. A avaliação do uso do laser não apresentou diferença estatisticamente significativa quanto ao efeito antiedematoso do laser pontual e sistêmico. A validação da metodologia demonstrou que o método de 
estereofotogrametria Vectra H1 e o software Face Sculptor são precisos para avaliação de diferenciação volumétrica em face.

Palavras-chave: Lasers. Fissura palatina. Estereofotogrametria. 


\begin{abstract}
Validation of the Vectra Face Sculptor software to assess volumetric changes in the analysis of the anti-oedematous effect of systemic or punctual laser in an area of fissured alveolar ridge grafted with autogenous bone
\end{abstract}

Cleft lip and palate are among the most common facial malformations, have aesthetic and functional implications, representing a rehabilitation challenge and mobilizing an extensive treatment protocol. This protocol presents several surgical procedures performed from the patient's first months of life to adulthood. Due to the extensive surgical protocol, the patient with cleft lip and palate is submitted to several treatments that promote great morbidity such as pain and edema. A fundamental surgery in the rehabilitation protocol is the bone graft in the fissure region, which promotes great morbidity to the patient, such as discomfort when eating, breathing and moving due to the development of edema and pain in the postoperative period. Lowlevel laser has been used successfully in bone regeneration in laboratory studies, as well as several studies point to the relationship between its use and the reduction of edema. The aim of this study was to validate the use of the Vectra Face Sculptor software to assess volumetric changes, as well as to evaluate the effect of systemic or punctual laser in an area of fissured alveolar ridge grafted with autogenous bone on postoperative edema.

The validation of the use of the stereophotogrammetric analysis was made from the measurement of the volumetric change in digital images with known dimensions and evaluation of the precision of the reproduction of the images made with the Vectra $\mathrm{H} 1$ equipment. To evaluate the effect of low-level laser, a sample of 18 individuals who underwent bone regeneration surgery was collected, which was divided into 3 groups $(n=6)$ : group 1 (control) - bone graft without laser application; group 2 (LBIL-6J) - bone graft with punctual laser application; group 3 (ILIB) - bone graft with systemic laser application. The laser used in Groups 2 and 3 were of the wavelength in the infrared (880nm $\square 10 \mathrm{~nm}$ ) and red (660 nm $\square 10 \mathrm{~nm}$ ) spectrum, respectively, with useful emitting power: $100 \mathrm{~mW} \pm 20 \%$, in the T1L - immediate postoperative, T2L - 24 hours postoperatively. The photographs were taken at the following times: TOF - 24 hours preoperatively, T1F - 24 hours postoperatively and T2F - 48 hours postoperatively. The evaluation of the use of the laser did not present a statistically significant difference 
regarding the antiedematous effect of the punctual and systemic laser. The validation of the methodology demonstrated that the Vectra $\mathrm{H} 1$ stereophotogrammetry method and the Face Sculptor software are accurate for evaluating face volumetric differentiation.

Key-words: Lasers. Cleft Palate. Photogrammetry. 


\section{LISTA DE FIGURAS}

\section{FIGURAS}

Figura 1 - Sobreposição automática dos cubos do PAR 1

Figura 2 - $\quad$ Avaliação da diferença de volume entre os cubos do PAR $1 \quad 40$

Figura 3 - Diferença volumétrica delimitada por padrões de cores e linhas 41

Figura 4 - $\quad$ Delimitação de uma área para servir de referência para as $\quad 41$ medições

Figura 5 - $\quad$ Medição da alteração do volume feita dentro da área estabelecida no programa Face Sculptor

Figura 6 - Seleção da área a ser sobreposta seguindo as orientações do fabricante

Figura 7 - Seleção da área a ser sobreposta com média abrangência dos detalhes da face

Figura 8 - Seleção da área a ser sobreposta com grande abrangência dos 43 detalhes da face

Figura 9 - Medição da alteração do volume feita dentro da área estabelecida no programa Mirror

Figura 10 - Edema com uma porção de silicona 45

Figura 11 - Edema com duas porções de silicona 45

Figura 12 - Edema com três porções de silicona $\quad 46$

Figura 13 - Edema de 95,70 $\mathrm{ml}$ em um paciente do grupo controle 47

Figura 14 - Edema de 31,79 $\mathrm{ml}$ em um paciente do grupo controle $\quad 47$

Figura 15 - Esquema da aplicação do LBI de maneira local 49

Figura 16 - Aplicação do LBI pelo protocolo ILIB 50

Figura 17 - Protocolo de aquisição fotográfica com a câmera posicionada 51 $30 \mathrm{~cm}$ abaixo do rosto do paciente e $45^{\circ}$ a sua esquerda

Figura 18 - Protocolo de aquisição fotográfica com a câmera posicionada 52 na altura no nariz do paciente e de maneira frontal

Figura 19 - Protocolo de aquisição fotográfica com a câmera posicionada $30 \mathrm{~cm}$ abaixo do rosto do paciente e $45^{\circ}$ a sua direita

Figura 20 - Imagens do período TOF e T1

Figura 21 - Sobreposição das imagens evidenciando a alteração de volume 54 
Figura 22 - Padrão de delimitação da diferença volumetria em linhas e cores

Figura 23 - Delimitação do edema seguindo a última linha completa gerada 55 pelo programa

Figura 24 - Delimitação do edema seguindo a última linha completa gerada 56 pelo programa

Figura 25 - Medição da diferença volumétrica entre as imagens T0F e T1F 56 


\section{LISTA DE TABELAS}

Tabela 1 - Avaliação da diferença volumétrica entre os cubos 59

Tabela 2 - Medição entre os grupos Sculptor e PA pelo teste T não pareado e o erro de Dahlberg

Tabela 3 - Medição entre os grupos Sculptor e MA pelo teste T não pareado e o erro de Dahlberg

Tabela 4 - $\quad$ Medição entre os grupos Sculptor e GA pelo teste T não pareado e o erro de Dahlberg

Tabela 5 - Segunda medição entre os grupos Sculptor e PA pelo teste Mann Whitney e o erro de Dahlberg

Tabela 6 - Segunda medição entre os grupos Sculptor e MA pelo teste T não pareado e o erro de Dahlberg

Tabela 7 - $\quad$ Segunda medição entre os grupos Sculptor e GA pelo teste T 60 não pareado e o erro de Dahlberg

Tabela 8 - Medição entre os grupos Sculptor em diferentes tempos teste T 60 não pareado e o erro de Dahlberg

Tabela 9 - Medição entre os grupos PA em diferentes tempos teste Mann 60 Whitney e o erro de Dahlberg

Tabela 10 - Medição entre os grupos MA em diferentes tempos teste T não 60 pareado e o erro de Dahlberg

Tabela 11 - Medição entre os grupos GA em diferentes tempos teste T não 60 pareado e o erro de Dahlberg

Tabela 12 - Avaliação da simulação de edema com 1 porção de silicona comparado pelo teste T e o erro de Dahlberg

Tabela 13 - Avaliação da simulação de edema com 2 porções de silicona comparado pelo teste T e o erro de Dahlberg

Tabela 14 - Avaliação da simulação de edema com 3 porções de silicona comparado pelo teste T e o erro de Dahlberg

Tabela 15 - Avaliação da primeira medição do edema por dois avaliadores comparados pelo teste T pareado e ICC

Tabela 16 - Avaliação da segunda medição do edema por dois avaliadores 62 comparados pelo teste T pareado e ICC 
Tabela 17 - Avaliação das medições do avaliador 1 comparados pelo teste T pareado e ICC

Tabela 18 - Avaliação das medições do avaliador 2 comparados pelo teste T pareado e ICC

Tabela 19 - Avaliação do edema pós-operatório 


\section{LISTA DE ABREVIATURA E SIGLAS}

LBI Laser de baixa intensidade

PA Pequena abrangência dos detalhes da face

MA Média abrangência dos detalhes da face

GA Grande abrangência dos detalhes da face

$\mathrm{ml} \quad$ mililitros

ICC Coeficiente de correlação interclasse

3D três dimensões 

SUMÁRIO

\begin{tabular}{|l|l|r|}
\hline $\mathbf{1}$ & INTRODUÇÃO E REVISÃO DE LITERATURA & $\mathbf{2 7}$ \\
\hline $\mathbf{2}$ & OBJETIVO & $\mathbf{3 5}$ \\
\hline $\mathbf{3}$ & MATERIAL E MÉTODOS & $\mathbf{3 9}$ \\
\hline 3.1 & $\begin{array}{l}\text { Validação do software Face Sculptor para avaliação de } \\
\text { diferenciação volumétrica }\end{array}$ & 41 \\
\hline 3.1 .1 & Avaliação da precisão da medição do software Face Sculptor & 41 \\
\hline 3.1 .2 & $\begin{array}{l}\text { Avaliação da precisão da sobreposição automática das fotos no } \\
\text { software Face Sculptor }\end{array}$ & 42 \\
\hline 3.1 .3 & Avaliação da acurácia das medições no software Face Sculptor & 46 \\
\hline 3.1 .4 & $\begin{array}{l}\text { Avaliação da reprodutibilidade das mediç̃̃es por diferentes } \\
\text { avaliadores }\end{array}$ & 48 \\
\hline 3.2 & Avaliação do edema pós operatório & 49 \\
\hline 3.2 .1 & População alvo & 49 \\
\hline 3.2 .2 & Critérios de Inclusão & 50 \\
\hline 3.2 .3 & Aspectos éticos da pesquisa & 50 \\
\hline 3.2 .4 & Tratamento & 50 \\
\hline 3.2 .5 & Aplicação do laser da baixa intensidade & 51 \\
\hline 3.3 & Métodos de avaliação do tratamento & 52 \\
\hline 3.3 .1 & Aquisição das imagens 3D utilizando Estereofotogrametria & 52 \\
\hline 3.3 .2 & Análise do edema pós-operatório nas imagens 3D utilizando o \\
\hline $\mathbf{4 .}$ & software Vectra Face Sculptor & $\mathbf{6 5}$ \\
\hline 4.1 & $\begin{array}{l}\text { Avaliação da precisão das medições feitas com o software Face } \\
\text { Sculptor }\end{array}$ & $\mathbf{6 3}$ \\
\hline 4.2 & $\begin{array}{l}\text { Avaliação da precisão da sobreposição automática das fotos no } \\
\text { software Face Sculptor }\end{array}$ & 59 \\
\hline 4.3 & Avaliação da acurácia das medições no software Face Sculptor \\
\hline 4.4 & Avaliação da reprodutibilidade das medições por diferentes \\
\hline 4.5 & Avaliação do edema pós-operatório & \\
\hline $\mathbf{5}$ & DISCUSSÃO & $\mathbf{6 3}$ \\
\hline
\end{tabular}




\begin{tabular}{|l|l|r|}
\hline 6 & CONCLUSÃO & 73 \\
\hline & REFERÊNCIAS & 77 \\
\hline & ANEXOS & 85 \\
\hline
\end{tabular}




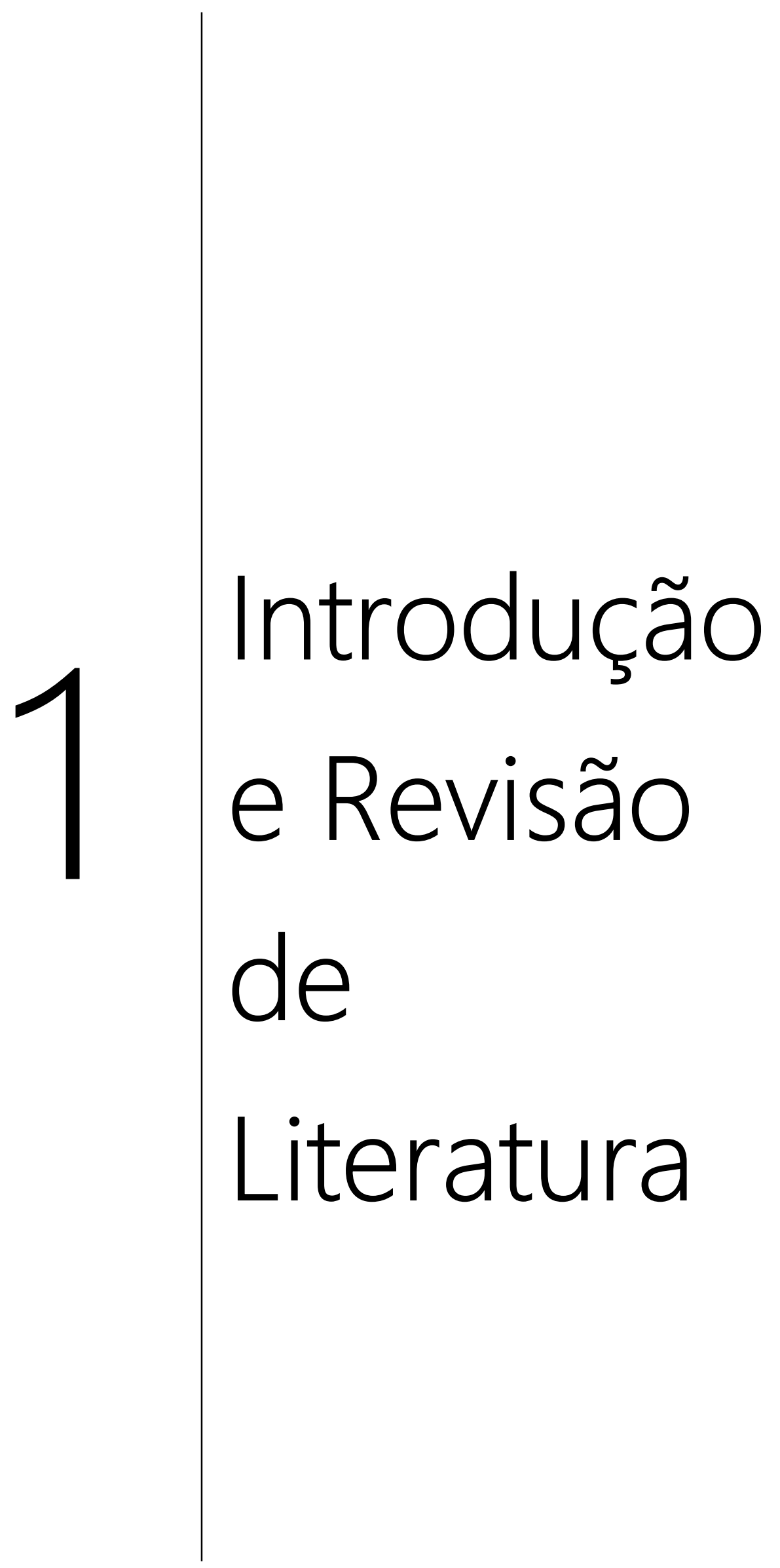





\section{INTRODUÇÃO E REVISÃO DE LITERATURA}

A fissura labiopalatina é uma anomalia congênita, que acomete indivíduos de todas as raças, resulta da falta de coalescência dos processos maxilares e frontal. $O$ seu diagnóstico pode ser realizado pelo exame de ultrassom; possui etiologia multifatorial (genética e ambiental) e ainda não existem muitos relatos na literatura esclarecendo maneiras de preveni-las, com exceção da utilização do ácido fólico durante o período gestacional (SHAW et al 1996; WILCOX et al 2007; FREITAS et al 2012a); estão entre os defeitos congênitos mais frequentes nos dias atuais, e são reconhecidas como um dos mais relevantes problemas de saúde pública pela Organização Mundial de Saúde (WHO 2002). No Brasil, registram-se 5.800 nascimentos por ano (WHO 2002).

As fissuras de lábio e palato são as mais comuns, variando de 39 a $92 \%$ (DALBEN et al 2002; FREITAS et al 2005), acarretam implicações estéticas por deixarem marcas na face e também desencadeiam problemas funcionais relacionados a oclusão, funcionamento do mecanismo velofaringeano e ouvido. Elas representam maior desafio reabilitador e mobilizam um protocolo de tratamento mais extenso (SILVA FILHO; FREITAS, 2007; FREITAS et al 2012a).

A partir da década de 60 , a reabilitação integral dos indivíduos com fissura tornou-se uma das prioridades médico-sociais dentro dos programas de saúde comunitária nos países desenvolvidos. As implicações psicológicas, estéticas e funcionais das fissuras são diversas (FREITAS et al 2012a) exigindo uma equipe multidisciplinar para reabilitar o indivíduo (FREITAS et al., 2013).

O protocolo ideal para a reabilitação dessas fissuras é iniciado aos três meses de vida com a cirurgia de queiloplastia, ou seja, fechamento do lábio, e os 12 meses é realizada a palatopastia (FREITAS et al 2012a). Durante a dentição mista, mais ou menos aos 8 anos, a ortodontia alinha os segmentos do rebordo para a realização de cirurgia para correção do mesmo com material de enxertia que pode ser osso autógeno ou biomateriais. O enxerto é realizado preferencialmente antes da erupção dos caninos permanentes. Após 4 meses, ao final da cicatrização, dá-se início a terapia ortodôntica pós-enxerto (FREITAS et al 2012b, FREITAS et al 2012c).

O enxerto ósseo alveolar tem como finalidade preencher a fissura óssea, dar suporte a base alar, eliminar fistulas oronasais, aumentar a estabilidade da maxila, permitir a erupção do dente na área enxertada, dar suporte aos dentes adjacentes, 
melhorar a simetria nasal, permitir a movimentação ortodôntica (FREITAS et al., 2012c, WU et al., 2018) e instalação de implantes osseointegráveis quando indicado (FREITAS et al., 2012c).

O enxerto de osso autógeno é considerado o padrão ouro para preenchimento do rebordo alveolar segmentado pela fissura, sendo que uso do osso medular é preferencial ao cortical devido à grande quantidade de células ósseas e sua capacidade de induzir a formação de novo osso. O enxerto ósseo proveniente da crista ilíaca tem sido o material de escolha devido a sua abundância, entretanto ele apresenta algumas desvantagens como morbidade da área doadora, dor pósoperatória, distúrbios sensoriais e claudicação, prolongando o tempo de internação do paciente e reabsorção óssea maior que $40 \%$ no primeiro ano após enxertia (WU et al., 2018).

Considerando todos esses aspectos negativos outras regiões têm sido escolhidas como área doadoras, como calvaria, tíbia e mandíbula, que promovem menor morbidade e menor reabsorção óssea (FREITAS et al., 2012c; WU et al., 2018).

A relação entre o componente cortical e medular do material utilizado como enxerto pode influenciar no sucesso em longo prazo da regeneração óssea. Enxertos provenientes de mandíbula (sínfise e área retromolar) apresentam como vantagem, sua capacidade de osteocondução. Entretanto, pelo predomínio de osso cortical, a sobrevivência de osteócitos pode estar comprometida, pois apresenta uma deficiência celular e vascularização prejudicada na superfície do periósteo e endósteo, dificultando a viabilidade celular (HALLMAN; THOR, 2008).

Uma das possíveis formas de compensar a desvantagem dos enxertos corticais, seria a utilização de fatores de crescimento e/ou mediadores biológicos que estimulem a osteogênese. O laser de baixa intensidade (LBI) tem sido utilizado com sucesso na regeneração óssea em estudos laboratoriais (SAYGUN et al 2008), préclínicos (ALMEIDA et al., 2014; CUNHA et al., 2014; FREITAS et al., 2018) e clínicos (FUJIHARA et al., 2006).

A utilização do LBI é baseada nos princípios de fotobiomodulação, receptores celulares nas mitocôndrias absorvem a energia luminosa o que desencadeia uma cascata de eventos. Essa atuação é dividida em duas etapas, sendo a primeira a liberação de Cálcio (Ca2+), e a segunda as consequências dessa liberação de Ca2+. Após absorvido, o LBI causa um aumento da temperatura local acionando uma resposta fisiológica regulatória, na região em que se acredita ser os alojamentos 
intracelulares de cálcio, que podem liberar Ca2+ sobre influência de diversos fatores. Os efeitos conhecidos de biomodulação induzida por laser são secundários e diretamente relacionada a liberação de $\mathrm{Ca2}+$. Entre os efeitos secundários existe o aumento da síntese de DNA e RNA, o aumento da síntese de ATP e sua acumulação, liberação de oxido nítrico e de formas de oxigênio reativos, mudanças na resposta intracelular perante a ação hormonal, assim como ativação de endo e exocitose e manutenção nos níveis de Ca2+ no complexo de Golgi (MOSKVIN 2017).

Esses efeitos ocorrem dependendo do contexto e do tipo celular e vão atuar diretamente ou indiretamente nos componentes do citosol, membrana celular, funções nucleares que controlam transcrição de genes e regulam respostas celulares como proliferação, migração, necrose e inflamação. Células que não absorveram fótons também podem ser afetadas indiretamente através das moléculas liberadas por células afetadas pelo LBI; células do sistema sanguíneo e linfático também podem ser afetadas, resultando em efeitos sistêmicos autócrino, parácrino e endócrino (CARROLL et al. 2014).

Sistemicamente existem efeitos da utilização do LBI usado localmente, esses efeitos são relacionados as moléculas que foram secretadas pelas células afetadas pelo laser, como fatores de crescimento e citocinas, mostrando melhora na formação de tecido ósseo ao redor de implantes (CARVALHO et al. 2014) e cicatrização de ferimentos (RODRIGO et al. 2009). Embora o LBI seja amplamente estudado e exista na literatura artigos que evidenciam sua influência em áreas distantes ao seu ponto de aplicação, poucos artigos abordam a utilização de forma sistêmica.

O LBI é usado sistemicamente através da irradiação do sangue, com o método intravascular ou com aplicação transcutânea sobre uma artéria (MOSKVIN 2017). A irradiação do tecido sanguíneo está relacionada a redução de doenças circulatórias, influenciando todas as células do sangue, a coagulação e o estado do plasma, assim com fatores estruturais da parede do vaso sanguíneo. A irradiação intravenosa (ILIB) aumenta a contagem de células vermelhas, reduz a taxa de sedimentação de eritrócitos, aumenta a função das células linfáticas e macrófagos, melhora o fluxo sanguíneo e a vaso dilatação (MIKHAYLOV 2015; MOMENZADEH et al. 2015).

Uma das principais áreas de pesquisa da atuação do LBI é sobre a regeneração óssea, fato que se explica devido ao grande volume de cirurgias de transplante ósseo realizadas. O tecido ósseo é o segundo material mais transplantado do corpo, depois 
do tecido sanguíneo, representando mais de 2,2 milhões de cirurgias ao redor do mundo (LEWANDROWSKI et al. 2000).

O osso autógeno é considerado o padrão ouro na enxertia óssea, embora apresente características desfavoráveis como, a necessidade de duas áreas cirúrgicas, maior comorbidade e rápida absorção, mesmo assim apresenta três características que corroboram a sua utilização: osteocondução, osteoindução e osteogênese (GRADO et al. 2018; AGHALOO \& HADAYA 2017). Destas três características, a osteoindução é importante para entender o papel do laser de baixa intensidade na regeneração óssea.

Osteoindução é a estimulação de células mesenquimais indiferenciadas em osteoblastos, processo mediado por uma cascata de sinais e ativações de diversos receptores inter e intracelulares, tais como BMP, bFGF e TGF-beta (GIANNOUDIS et al. 2005). O real efeito do LBI na regeneração óssea ainda é discutido, não é certo se seu efeito é dado através da estimulação das células mesenquimais indiferenciadas, da direta estimulação de osteoblastos ou do aumento da produção de fatores de crescimento (BOSCO et al. 2016). Embora não seja consenso a exata função do LBI, trabalhos como o de Pyo e colaboradores (PYO et al. 2013) mostraram o efeito positivo do LBI em osteoblastos aumentando a expressão de osteocalcina, BMP-2 e TGF- $\beta 1$.

Outro fator crucial para o sucesso dos enxertos ósseos é a angiogênese, fornecendo nutrientes, oxigênio, células imunológicas, células mesenquimais indiferenciadas e fatores de crescimento para a área enxertada (SAGHIRI et al. 2016). Tanto a utilização sistêmica ou local do LBI mostra efeitos positivos na circulação, o trabalho realizado por Tim e colaboradores (TIM et al. 2016), estudaram a utilização de LBI em defeitos ósseos criados em tíbia de ratos, mostrando uma maior expressão de fator de crescimento de vaso endotelial. Na irradiação de laser no sangue também é relatada uma influência positiva na angiogênese, fluxo sanguíneo e vaso dilatação (MIKHAYLOV 2015).

O LBI também reduz o edema, atuando diretamente ou indiretamente no sistema linfático, assim como aumentando sua função (MIKHAYLOV 2015, CARROLL et al. 2014). A metodologia comumente proposta para analisar este efeito do laser após cirurgias é utilização de uma fita métrica, realizando medições da distancias entre pontos anatómicos antes e após a cirurgia (CUNHA et al., 2013), porém esse 
método avalia apenas a alteração linear da distância entre os pontos, sendo assim não avalia o real volume em três dimensões (PISO et al. 2001).

Novas metodologias têm surgido no mercado como a estereofotogrametria que é a análise de imagens em três dimensões, com esse método é possível realizar medições de distância, angulação e volume entre diferentes pontos, essa tecnologia está sendo uma das técnicas mais aplicadas nos estudos envolvendo análise de tecidos moles (de MENEZES et. al 2009; ROSATI et. al 2014; CAMISON el. al 2017; GIBELLI et. al 2018).

A análise estereofotogramétrica é utilizada para realizar medições e planejamentos em modelos digitalizados em três dimensões. Através da sobreposição de imagens obtidas em diferentes tempos é possível realizar o dimensionamento volumétrico avaliando-se assim o edema pós-operatório (van der VLIS et. al 2014).

Existem diversas máquinas para realizar as tomadas fotográficas em três dimensões, assim como diversos softwares para realizar as medições de estereofotogrametria (van der Meer et al. 2014). A utilização na máquina portátil Vectra H1 juntamente com o software de medição Vectra Mirror (Canfield Scientific, Fairfield, NJ, EUA) foi validada realizar análise facial (CAMISON el. al 2017; GIBELLI et. al 2018), provando ser confiável para a tomada de fotografias em três dimensões e avaliações de medidas lineares, angulares e de área de superfície (GIBELLI et. al 2018). Entretanto, a utilização do sistema da Vectra H1 e o software Vectra Face Sculptor ainda não foram validados para realização de medições de alterações volumétricas na face.

O software Face Sculptor é um programa para análise de estereofotogrametria, no qual se realiza da junção das imagens tiradas pela máquina Vectra $H 1$, que formarão a imagem em três dimensões. Atualmente para realizar medições na face é utilizado junto da máquina Vectra H1 o software Vectra Mirror, software esse já validado para realizar medições lineares em imagens já costuradas pelo software Face Sculptor. Para realizar medições precisas no Vectra Mirror é necessário demarcar pontos anatômicos na face do paciente antes do registro fotográfico, marcação essa, que não é viável em pacientes com grande edema na face, devido a dificuldade de localização desses pontos anatômicos para se ter uma medição precisa. Outro fator que vai contra a utilização do Vectra Mirror seria o fato da medição estar restrita a uma área delimitada por pontos anatômicos. 
A avaliação da diferenciação volumétrica é feita de maneira diferente no programa Face Sculptor, uma vez que nesse programa as imagens a serem comparadas são sobrepostas automaticamente e o próprio programa realça a área com alteração de volume, sugerindo uma avaliação mais precisa da alteração de volume, porém ainda sem validação da técnica. 


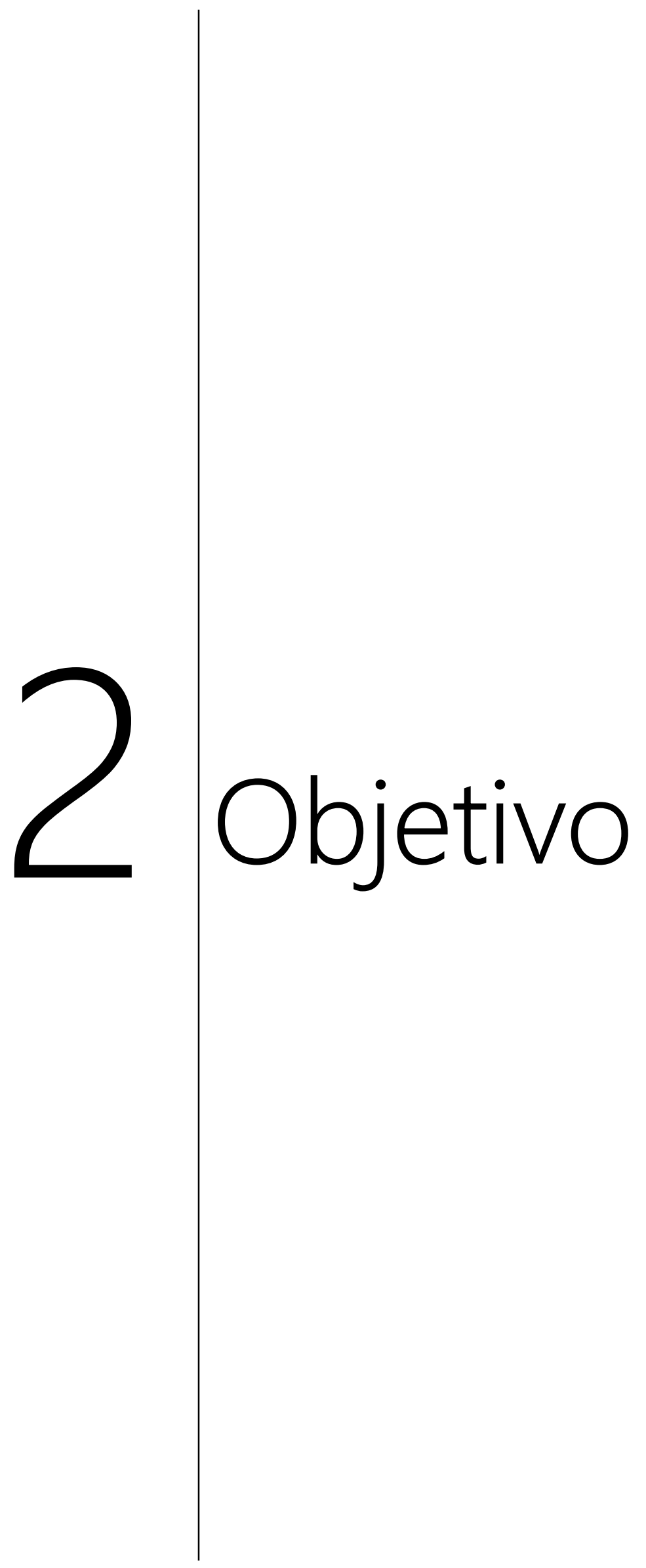





\section{OBJETIVO}

Validar a utilização do software Vectra Face Sculptor para avaliação de alteração volumétrica.

Avaliar o efeito do laser sistêmico ou pontual em área de rebordo alveolar fissurado enxertado com osso autógeno sobre o edema pós-operatório. 



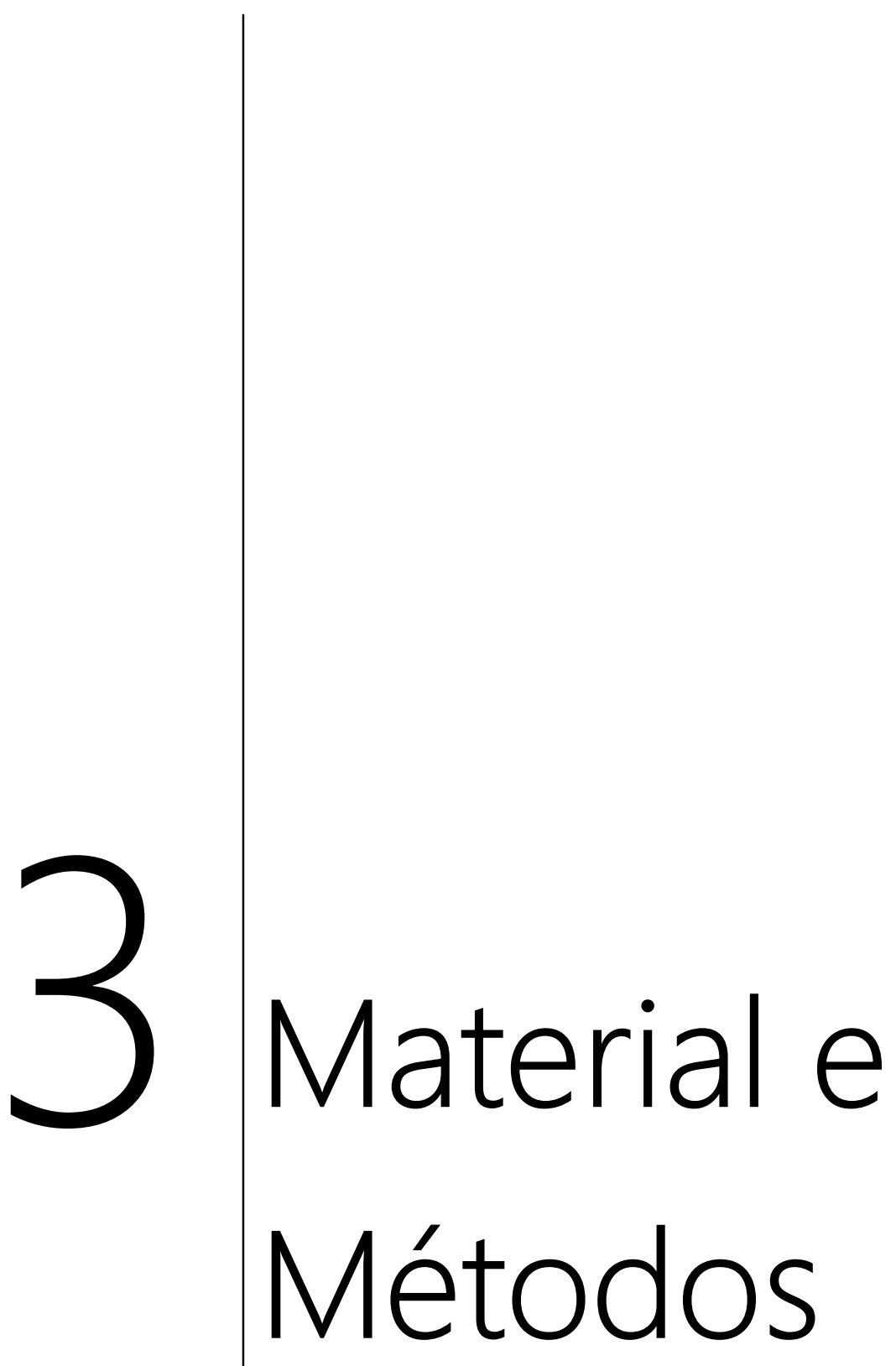





\section{MÉTODOS}

3.1 Validação do software Face Sculptor para avaliação de diferenciação volumétrica

A validação da utilização do software Face Sculptor (Canfield Scientific, Inc, Fairfield, NJ, EUA) foi feita a partir da avaliação da precisão da medição, da precisão da sobreposição automática das imagens, da acurácia das avaliações e reprodutibilidade das medições por diferentes avaliadores.

\subsubsection{Avaliação da precisão da medição do software Face Sculptor}

Para avaliar a precisão da medição realizada pelo software foram gerados quatro cubos digitais com dimensões conhecidas no software Rhinoceros 3D (McNeel North America, Seattle, WA, USA) e divididos em dois grupos. Os cubos foram desenhados em pares, o primeiro grupo de cubos (PAR 1) com dimensões $5 \times 5 \times 5 \mathrm{~cm}$ e outro de $5 \times 5 \times 6 \mathrm{~cm}$, e o segundo grupo de cubos (PAR 2) com dimensões de $0,1 \times 0,1 \times 0,1 \mathrm{~mm}$ e o outro $0,1 \times 0,1 \times 0,11 \mathrm{~mm}$. Então os cubos foram exportados no formato ".tom" para ser possível realizar as medições no software Face Sculptor.

Os pares de cubos foram exportados para o software Face Sculptor e realizado sua sobreposição automática. Com a ferramenta de aferição de volume foi feita a medição da alteração volumétrica em ambos os pares de cubos (Figura 1 e 2).

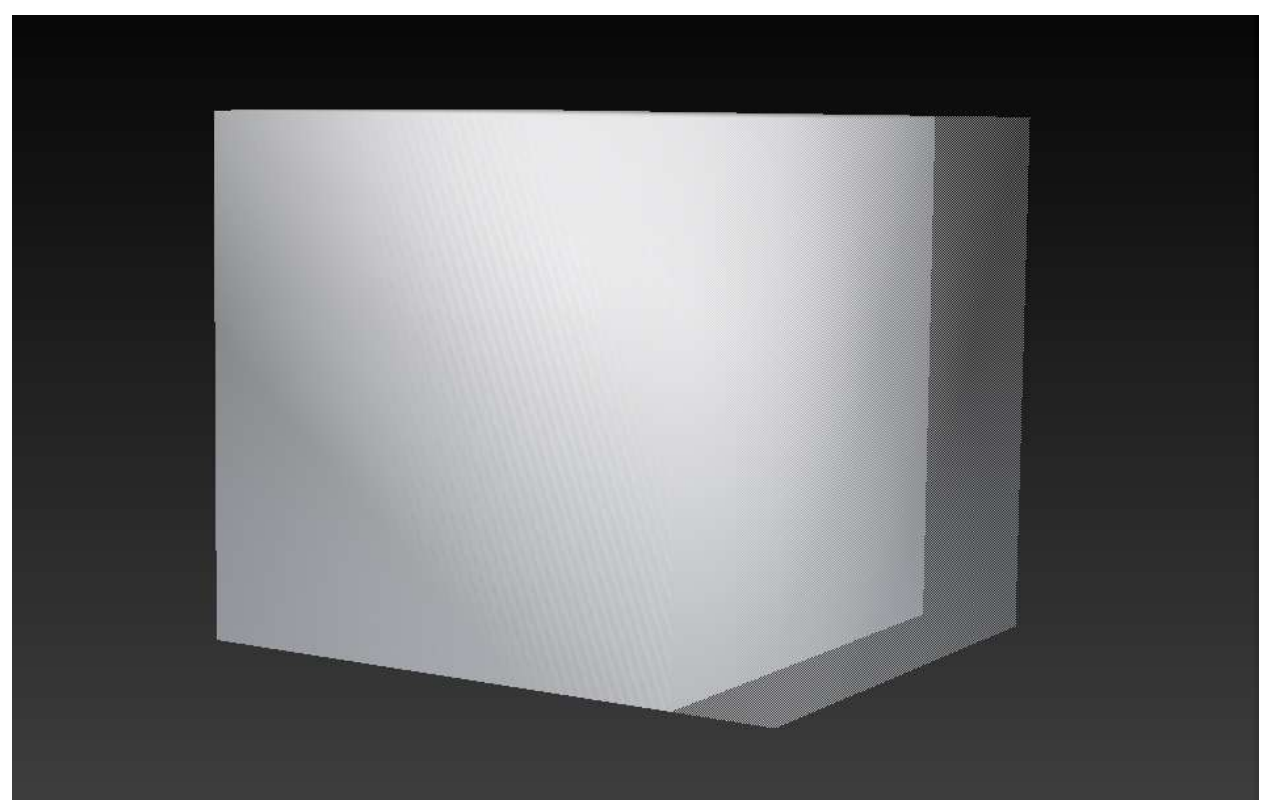

Figura 1 - Sobreposição automática dos cubos do PAR 1 


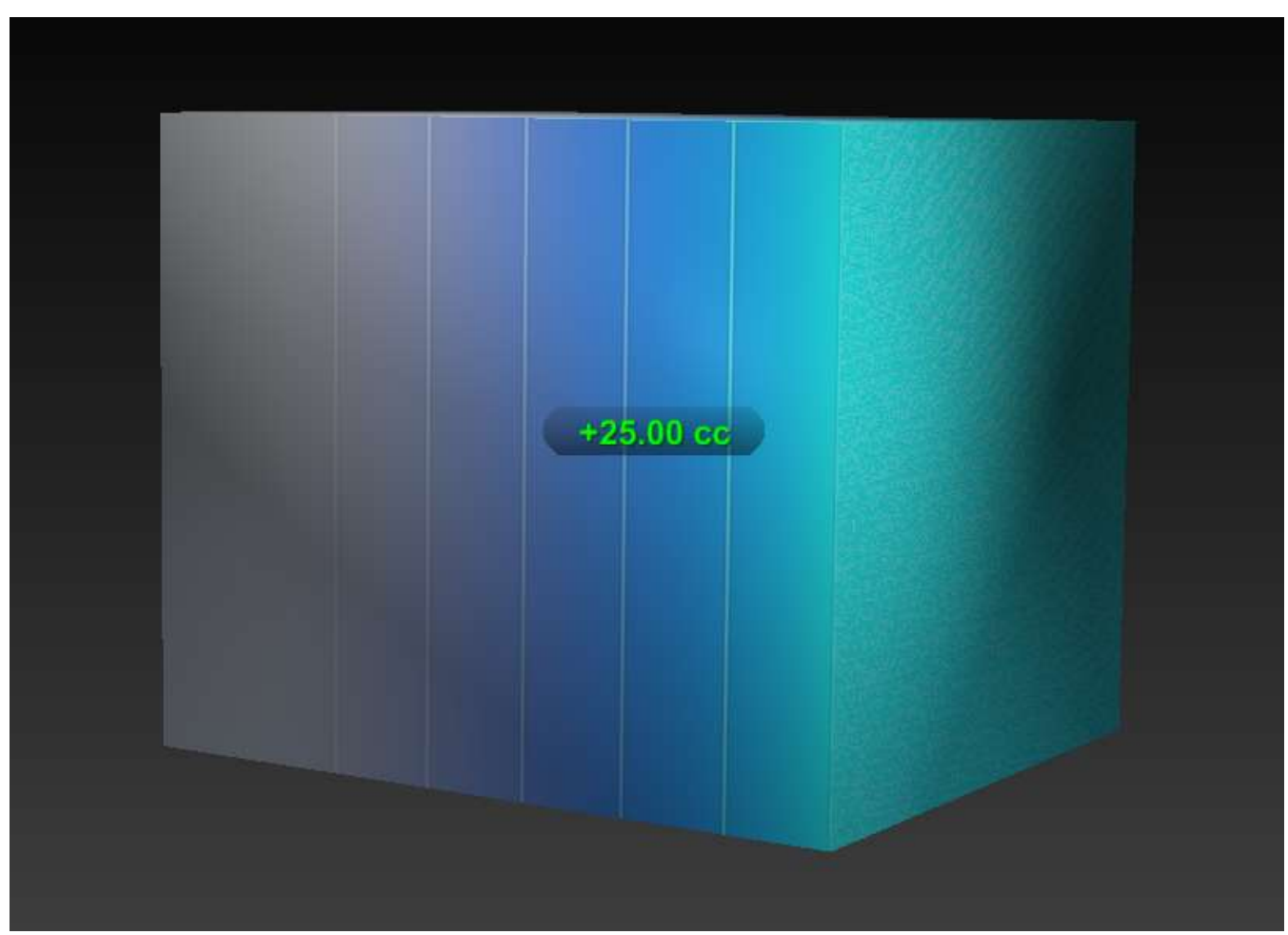

Figura 2 - Avaliação da diferença de volume entre os cubos do PAR 1.

3.1.2 Avaliação da precisão da sobreposição automática das fotos no software Face Sculptor

Para avaliar se a sobreposição automática das diferentes fotos é precisa foram realizadas comparações com medições realizadas no software Vectra Mirror, que foi validado para análise de medições lineares, angulares e de área, no qual a sobreposição de imagens é feita de maneira manual.

A aferição da diferença volumétrica no Face Sculptor se dá pelo destaque da área com diferenciação volumétrica por um padrão de cores e por delimitação desta área por padrões de linhas (Figura 3). Já no Mirror não existe tal delimitação tornandose subjetiva a área em que é feita a medição volumétrica. Sendo assim, para ser possível a medição da mesma área em ambos os programas, foram tiradas fotos do rosto de um indivíduo com uma área delimitada em seu rosto, para servir de margem para medição do volume (Figura 4). 


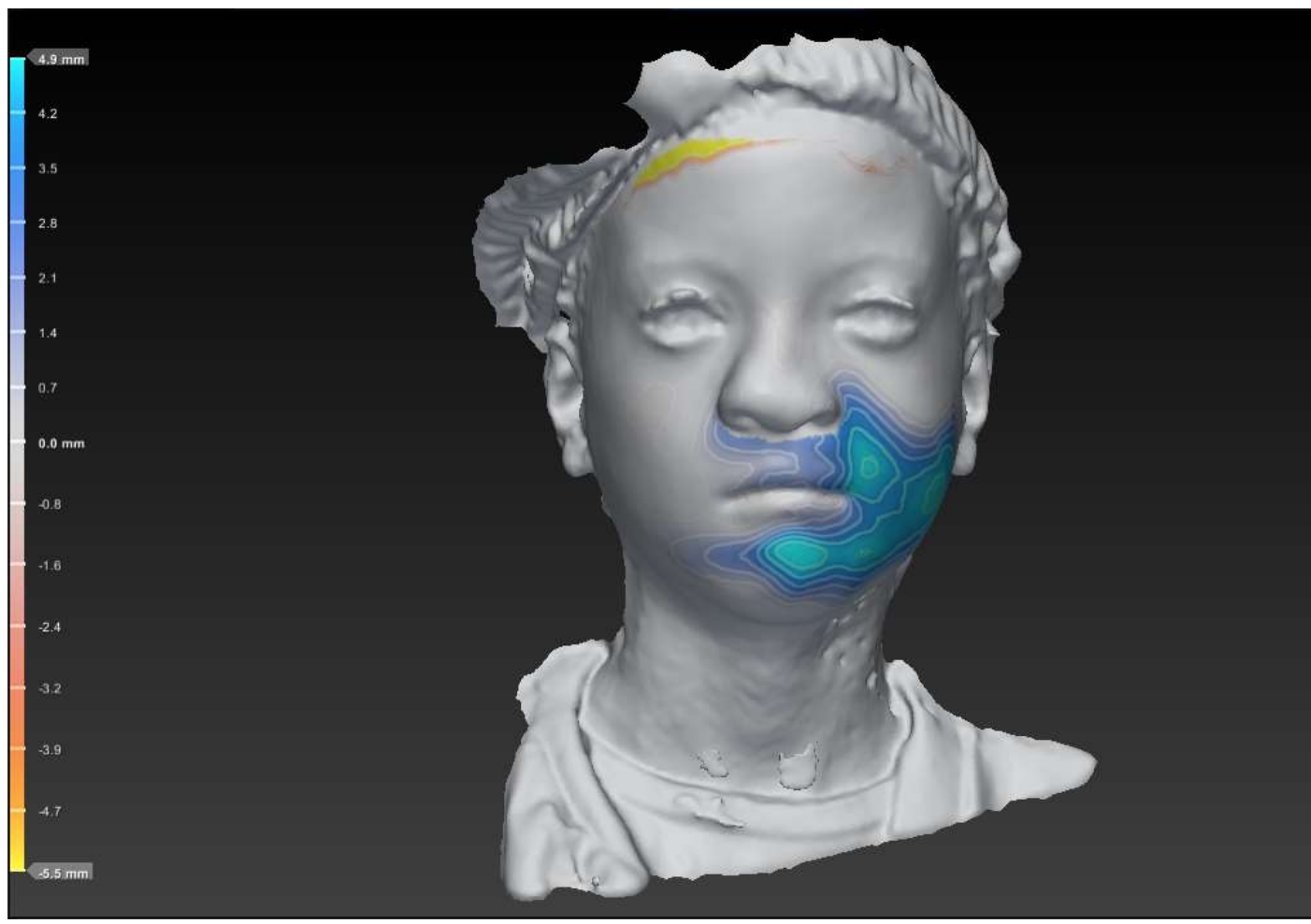

Figura 3 - Diferença volumétrica delimitada por padrões de cores e linhas.

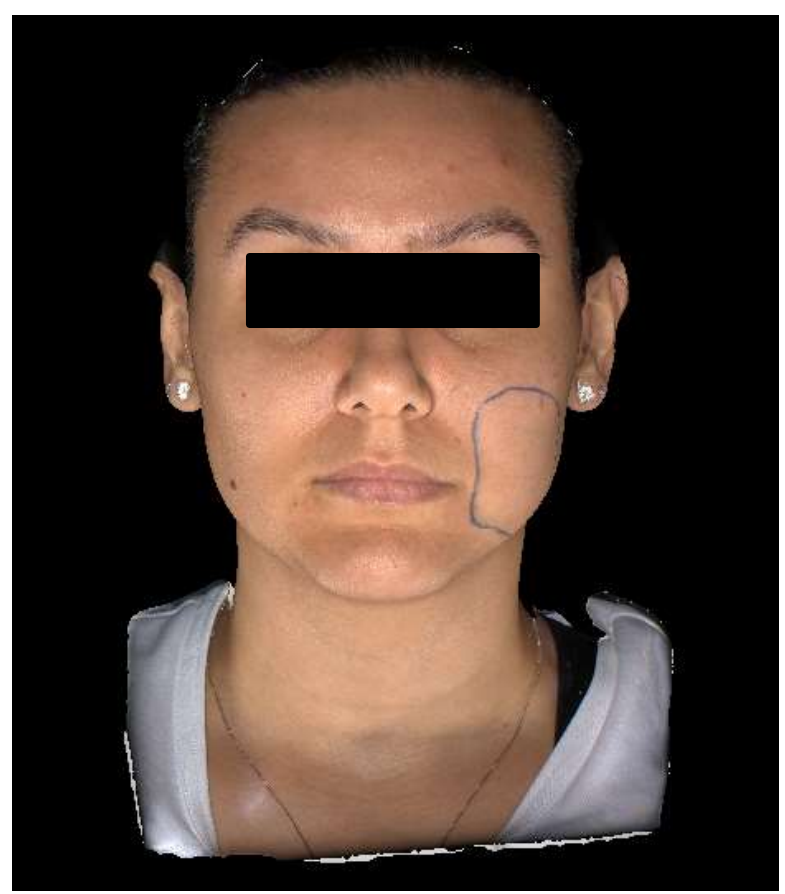

Figura 4 - Delimitação de uma área para servir de referência para as medições.

Foi desenhado um círculo da face do indivíduo e feita a simulação de um edema com a colocação de uma porção de silicona de condensação (Optosil, Heraeus Kulzer $\mathrm{GmbH}$, Hanau, Germany) entre os dentes e a mucosa jugal, na região dos dentes 23 a 25. Em seguida foram feitas duas tomadas fotográficas, uma com a silicona de condensação simulando um edema e outra sem a silicona. 
$\mathrm{Na}$ avaliação do programa Face Sculptor as imagens foram sobrepostas automaticamente pelo programa e em seguida foram feitas as medições (Figura 5).

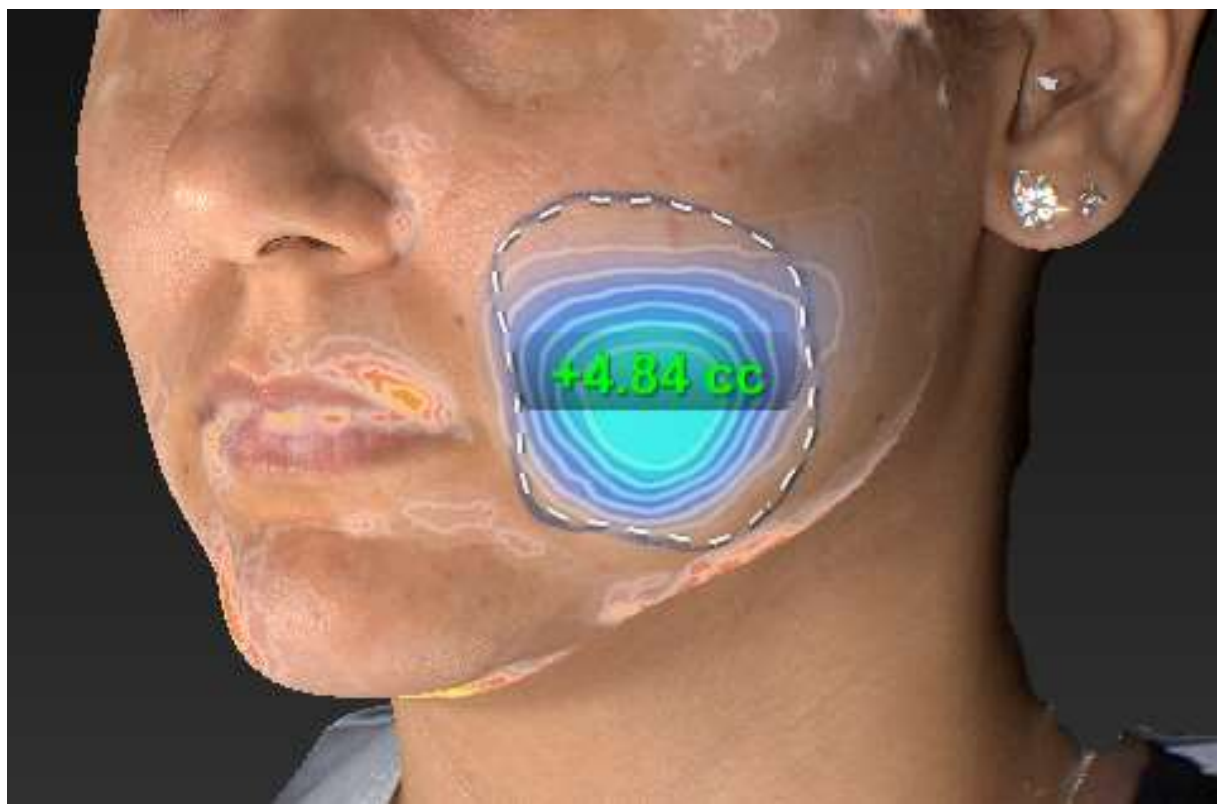

Figura 5 - Medição da alteração do volume feita dentro da área estabelecida no programa Face Sculptor.

No programa Mirror as imagens são sobrepostas a partir da identificação de áreas semelhantes em ambas as fotos, foram feitas três sobreposições diferentes:

- Sobreposição de pequena abrangência dos detalhes da face (PA), seguindo as orientações da fabricante do programa (Figura 6)

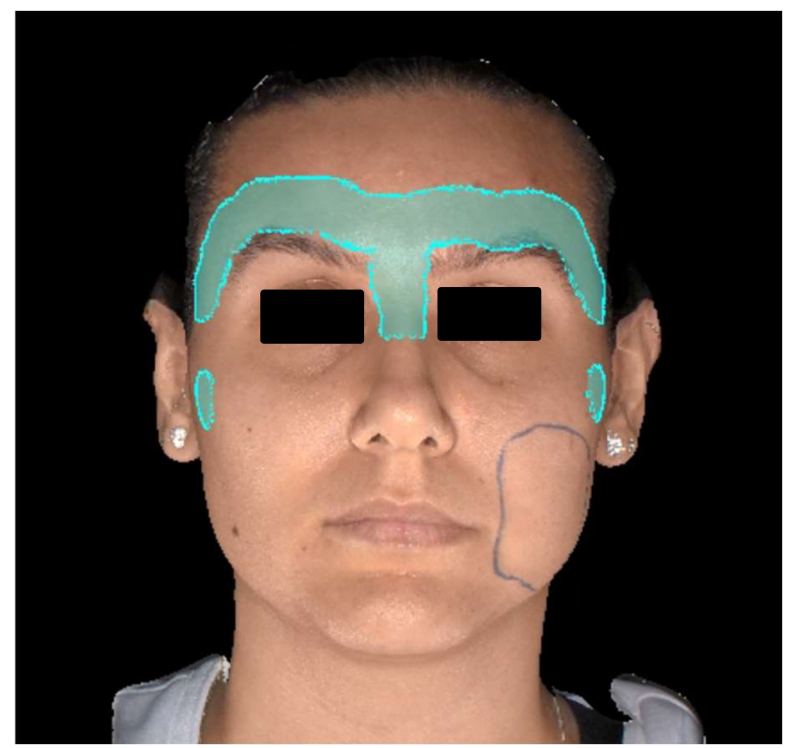

Figura 6 - Seleção da área a ser sobreposta seguindo as orientações do fabricante.

- Sobreposição com média abrangência dos detalhes da face (MA) (Figura 7) 


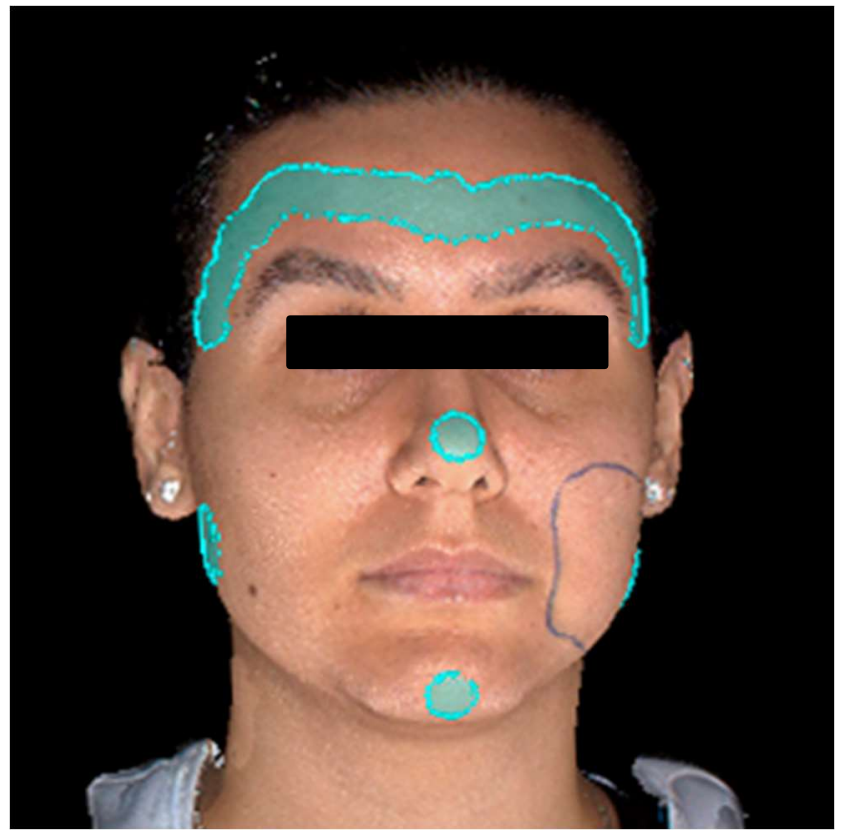

Figura 7 - Seleção da área a ser sobreposta com média abrangência dos detalhes da face.

- Sobreposição com grande abrangência dos detalhes da face (GA) (Figura 8)

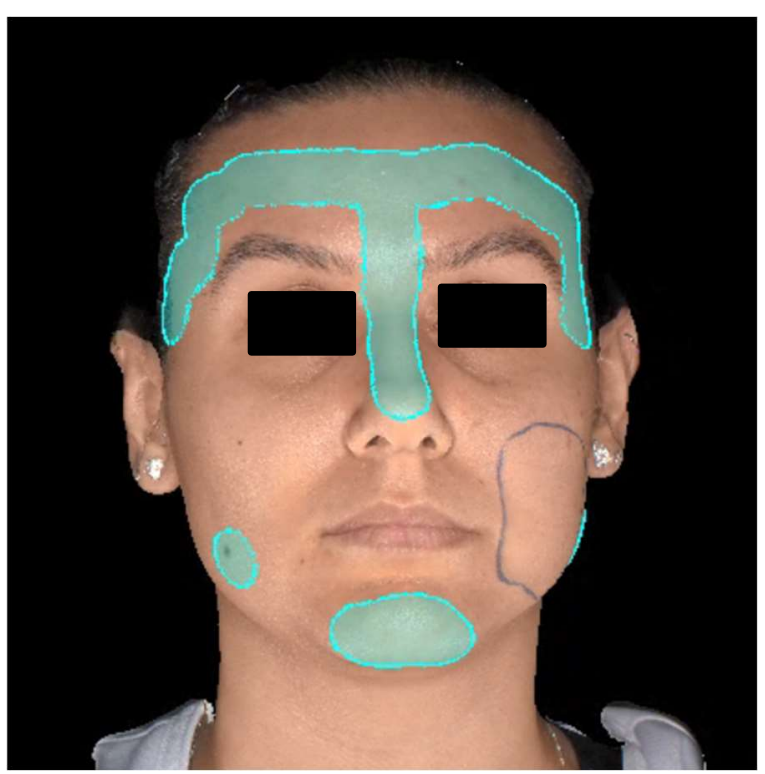

Figura 8 - Seleção da área a ser sobreposta com grande abrangência dos detalhes da face.

Após as sobreposições manuais no software Mirror, foram feitas as medições (Figura 9). 


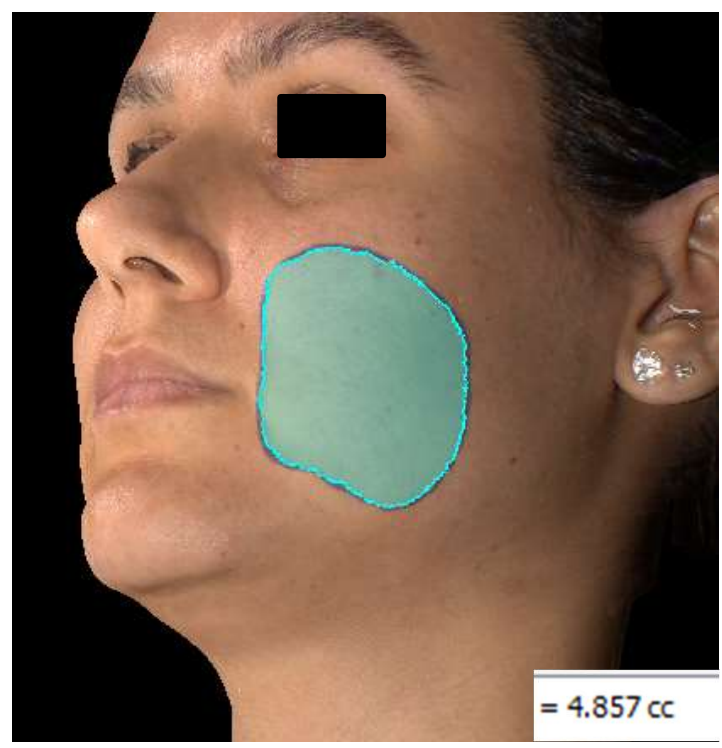

Figura 9 - Medição da alteração do volume feita dentro da área estabelecida no programa Mirror.

Após um período de sete dias foram feitas novas medições em ambos os programas e a sobreposição manual foi novamente feita seguindo as mesmas orientações.

\subsubsection{Avaliação da acurácia das medições no software Face Sculptor}

Para avaliar a reprodutibilidade da delimitação da área de diferenciação volumétrica pelo programa Face Sculptor, foram feitas simulações de edema em um paciente e feita duas tomadas fotográficas, uma em sequência da outra, a fim de identificar se o programa iria delimitar sempre a mesma alteração volumétrica.

Foram criadas diferentes alterações volumétricas com o uso de silicona de condensação (Optosil, Heraeus Kulzer GmbH, Hanau, Germany), criando edemas com uma, duas e três porções de silicona (Figura 10 - 12). 


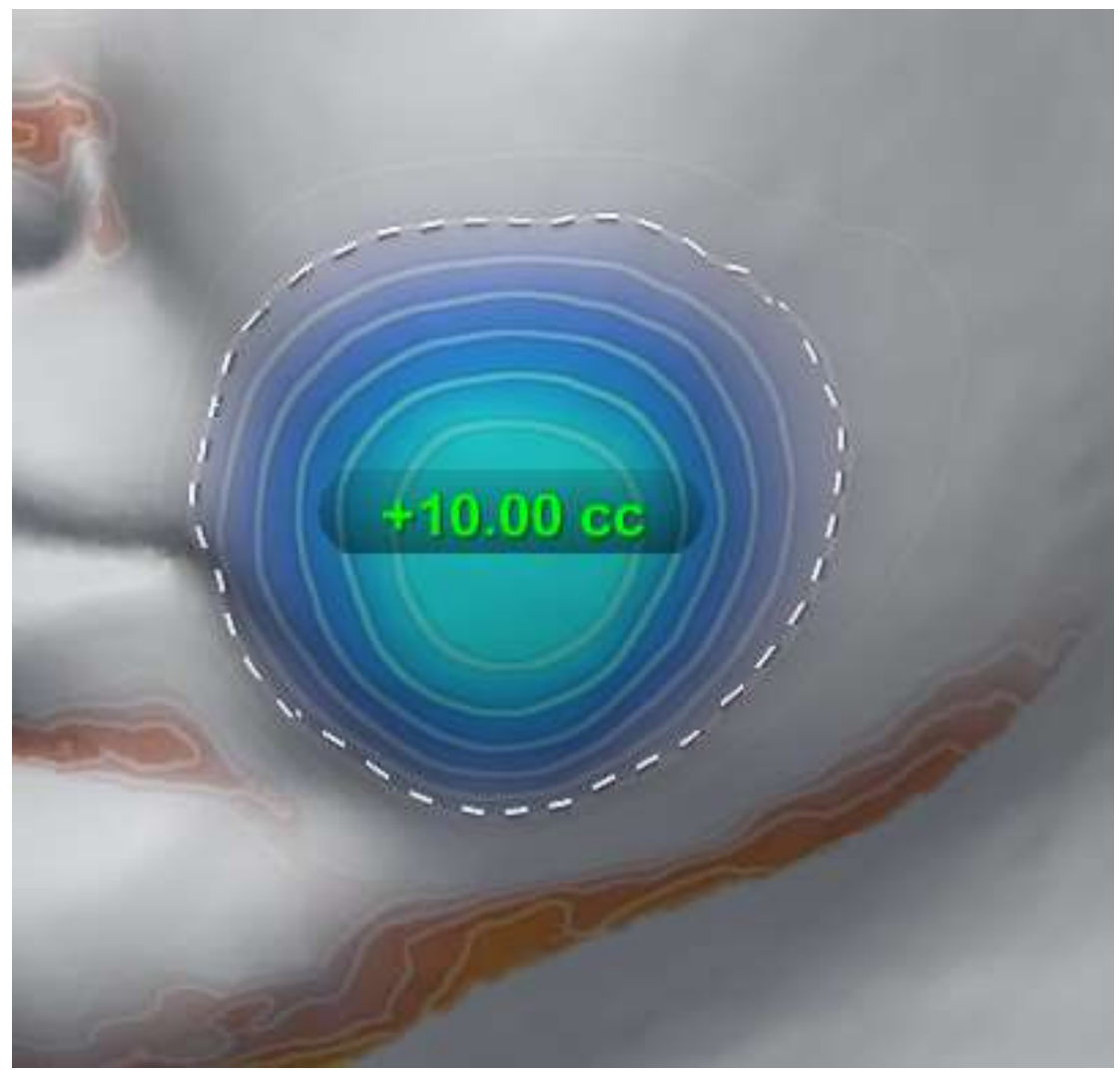

Figura 10 - Edema com uma porção de silicona.

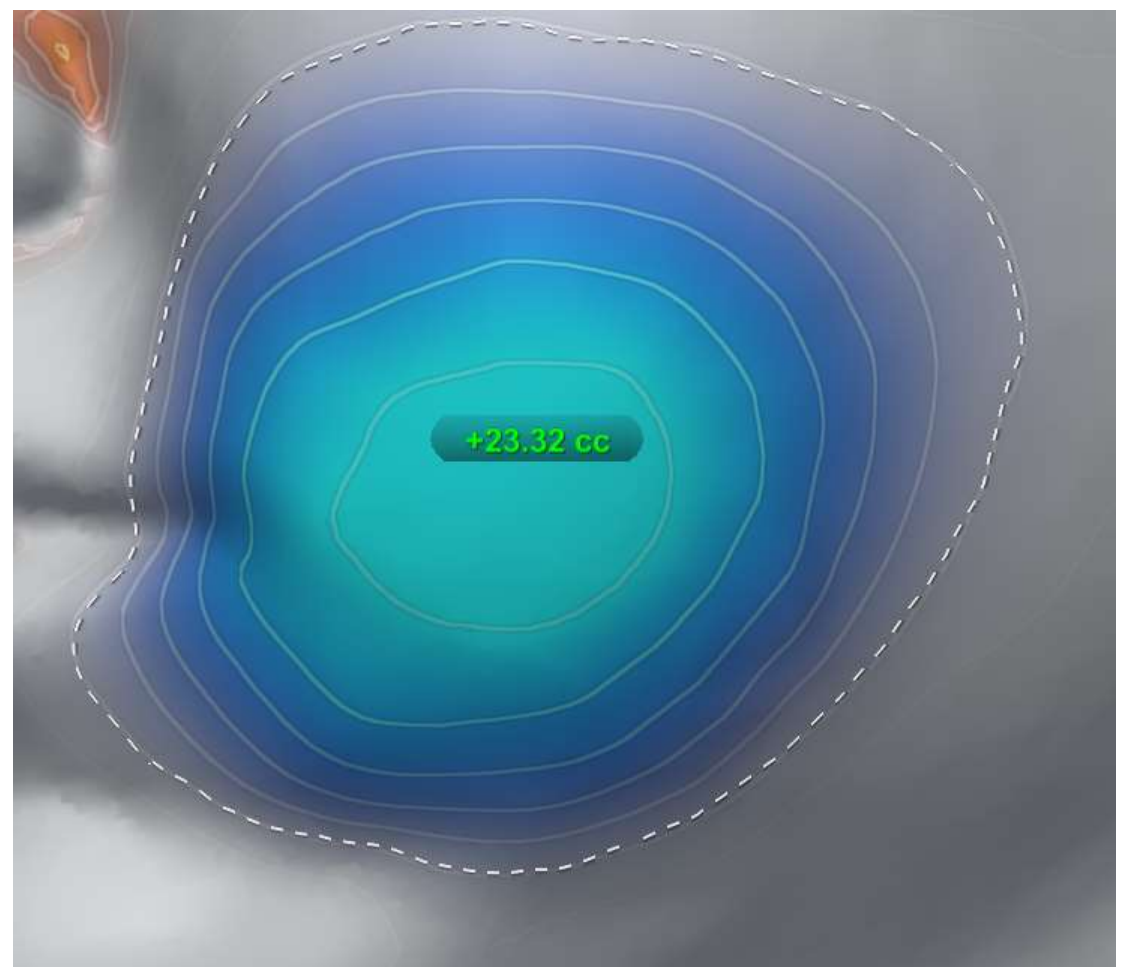

Figura 11 - Edema com duas porções de silicona. 


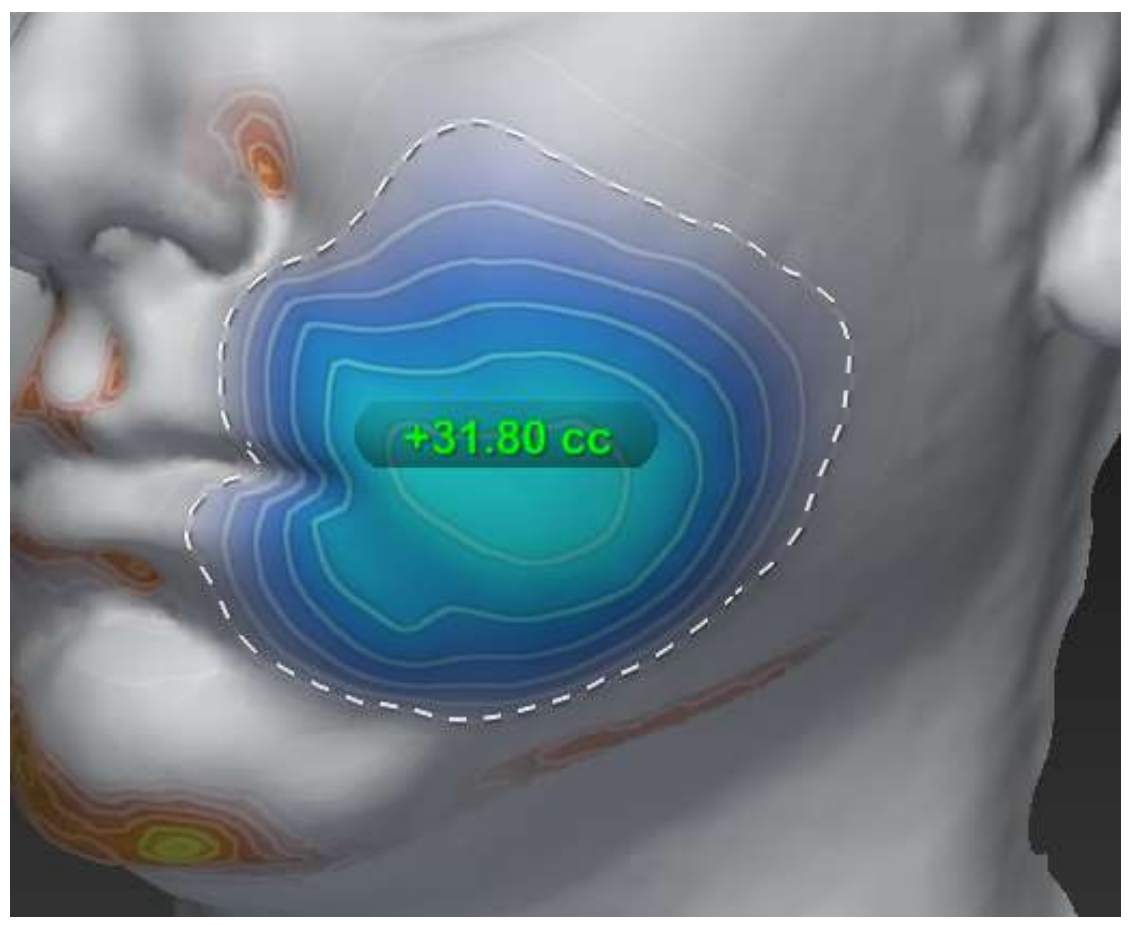

Figura 12 - Edema com três porções de silicona.

3.1.4 Avaliação da reprodutibilidade das medições por diferentes avaliadores.

Para avaliar a reprodutibilidade da medição inter e intra-examinador foram feitas medições, por dois avaliadores e repetidas após uma semana, do edema gerado no grupo controle submetido a cirurgia de enxerto autógeno em área de fissura (figura 13 e 14). 


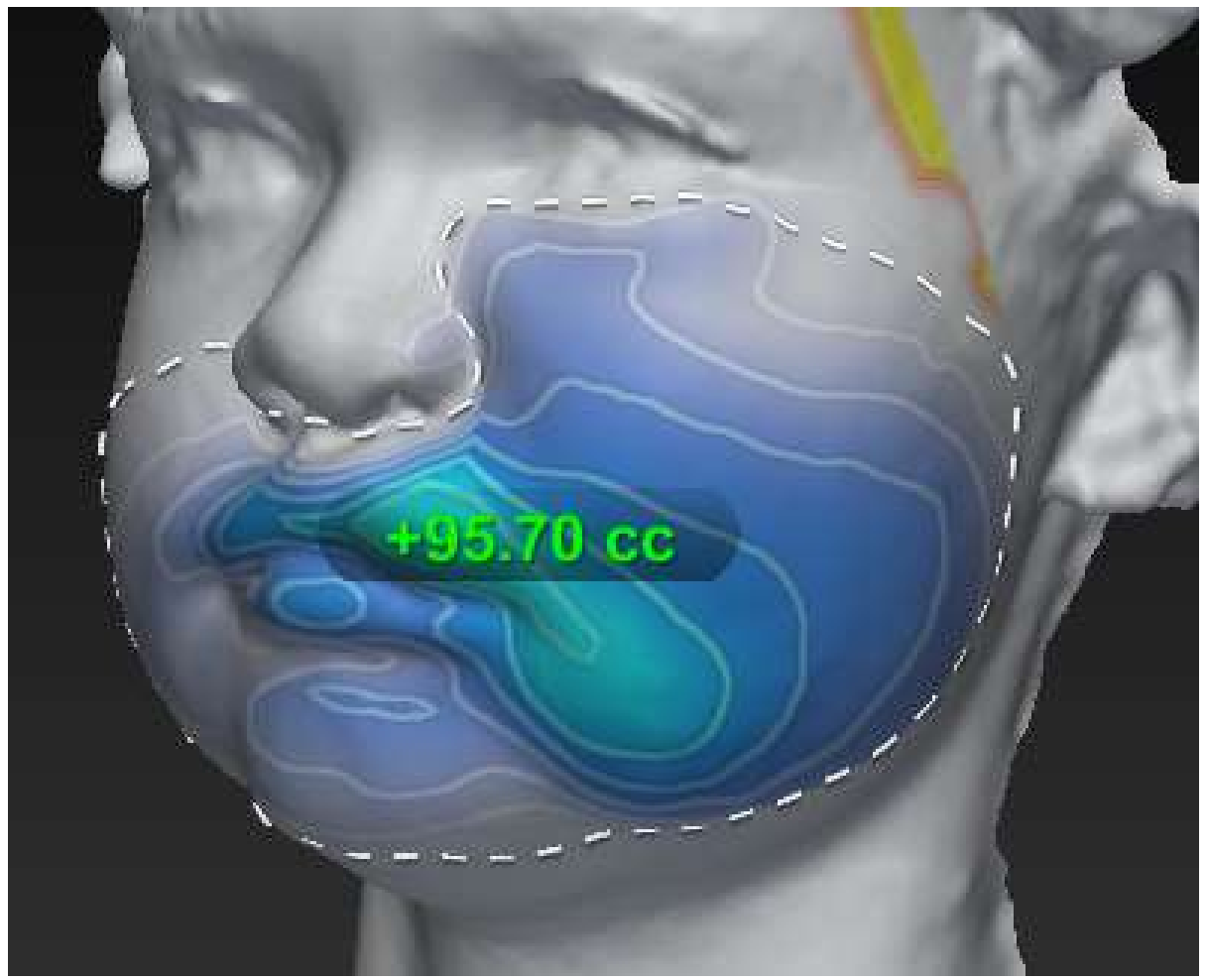

Figura 13 - Edema de $95,70 \mathrm{ml}$ em um paciente do grupo controle

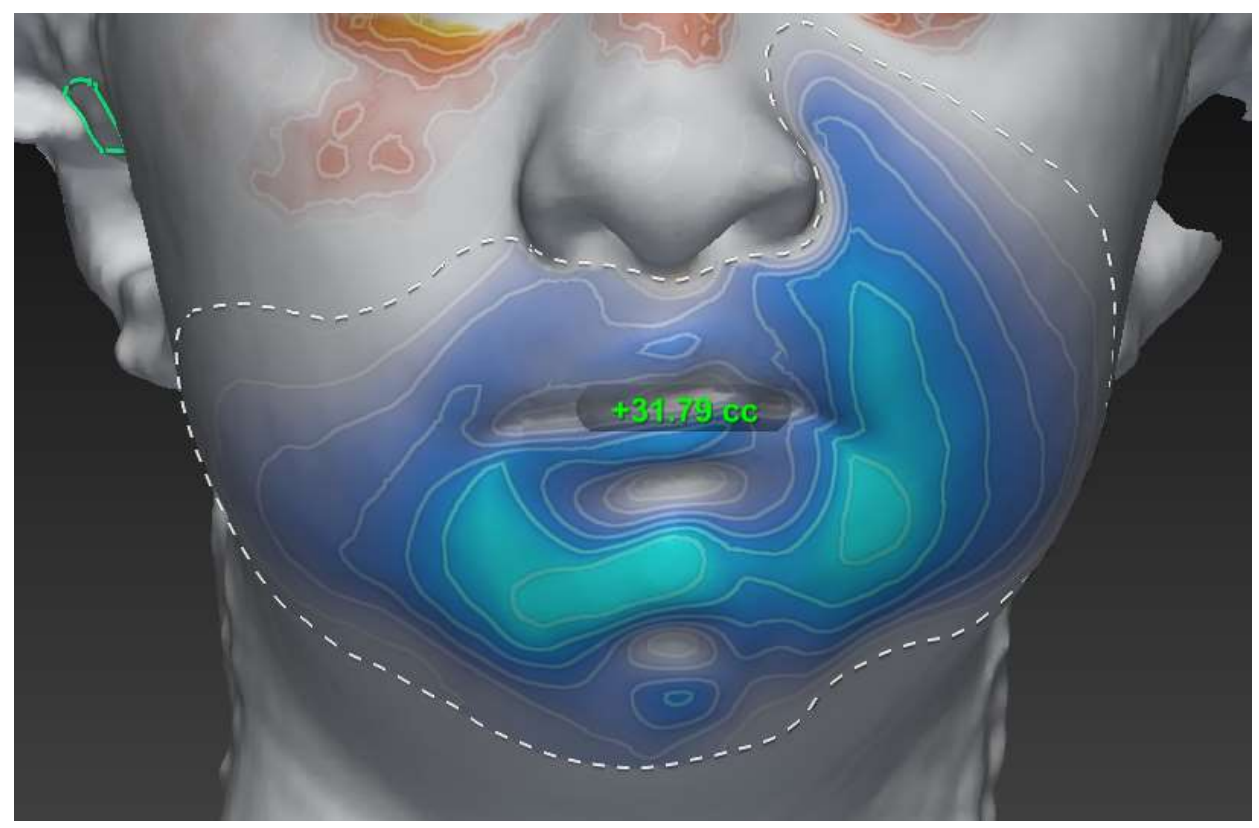

Figura 14 - Edema de $31,79 \mathrm{ml}$ em um paciente do grupo controle

3.2 Avaliação do edema pós operatório

\subsubsection{População alvo}

A população foi constituída de 18 indivíduos com fissura labiopalatina. Esses indivíduos serão provenientes do Hospital de Reabilitação de Anomalias Craniofaciais, Universidade de São Paulo. 


\subsubsection{Critérios de Inclusão}

- Indivíduos com fissura transforame incisivo unilateral, de 9 a 15 anos de ambos os sexos.

- Indivíduos saudáveis, sem alterações sistêmicas

- Não fumantes

- Ausência de doença periodontal

- Enxerto ósseo autógeno de sínfise mentoniana

- Indivíduos que recebem o protocolo padrão de pós-operatório do HRAC

- Indivíduos que permaneçam o período de 48 horas no HRAC

\subsubsection{Aspectos éticos da pesquisa}

O estudo foi aprovado pelo do Comitê de Ética em Pesquisa em Seres Humanos do Hospital de Reabilitação de Anomalias Craniofaciais do HRAC/USP, CAAE 01436618.4.0000.5441. Os participantes que aceitaram participar da pesquisa assinaram os Termos de Consentimento Livre e Esclarecido e de Assentimento.

\subsubsection{Tratamento}

A técnica cirúrgica empregada no HRAC preconiza uma incisão vestibular oblíqua à meia distância entre o centro da coroa do primeiro molar e a papila gengival mesial, prosseguindo-se com uma incisão intra-sulcular que se estende até a margem lateral da fissura, contorna seu limite gengival, atingindo o segmento contralateral da maxila, tendo seu fim na região intra-sulcular dos incisivos centrais. O retalho descolado é total a partir dessa incisão oblíqua inicial. Procede-se ao descolamento e reposicionamento superior da mucosa de assoalho nasal, seguido por sua sutura, para fechamento de fístula buconasal, e criação de espaço físico a ser preenchido pelo material de enxertia. A mucosa palatina também é divulsionada e suturada. Após cuidadosamente acomodar o enxerto ósseo em bloco, o retalho vestibular é reposicionado até o total recobrimento do osso inserido e de toda a extensão óssea divulsionada, sem tensão; suas bordas são debridadas e, por fim, realiza-se a sutura das incisões com pontos simples.

Para a obtenção do enxerto de sínfise mandibular, realiza-se incisão a aproximadamente $5 \mathrm{~mm}$ da linha mucogengival entre os caninos inferiores, decíduos 
ou permanentes, com retalho total, expondo toda a sínfise até sua base no sentido apical e até a emergência dos nervos mentonianos látero-lateralmente. A osteotomia é desenhada respeitando distância de $5 \mathrm{~mm}$ dos ápices dos dentes ântero-inferiores e prevê a remoção de bloco corticomedular. A borda inferior da sínfise é mantida intacta. A sutura é feita por planos. A medicação pós-operatória será ministrada pelo cirurgião buco maxilo de acordo com o protocolo do HRAC e será a mesma para todos os grupos.

\subsubsection{Aplicação do laser da baixa intensidade}

Os 18 indivíduos foram divididos em três grupos:

Grupo 1 (controle) - enxerto ósseo alveolar na área do rebordo alveolar fissurado.

Grupo 2 (LBIL) - enxerto ósseo com aplicação de laser local

Grupo 3 (ILIB) - enxerto ósseo com aplicação de laser sistêmico

O laser utilizado nos Grupos 2 e 3 foi o Therapy EC no comprimento de onda no espectro infravermelho $(880 \mathrm{~nm} \pm 10 \mathrm{~nm})$ e do vermelho $(660 \mathrm{~nm} \pm 10 \mathrm{~nm})$ respectivamente, com potência útil emissor: $100 \mathrm{~mW} \pm 20 \%$.

Na forma pontual foi aplicada 6J por ponto, em 7 pontos extra orais (Figura 15) e na forma ILIB foi seguido o protocolo ILIB de 30 minutos, com aplicação do laser de maneira transcutânea sobre a artéria radial (Figura 16), ambos nos tempos T1L - pósoperatório imediato, T2L - 24 horas pós-operatório

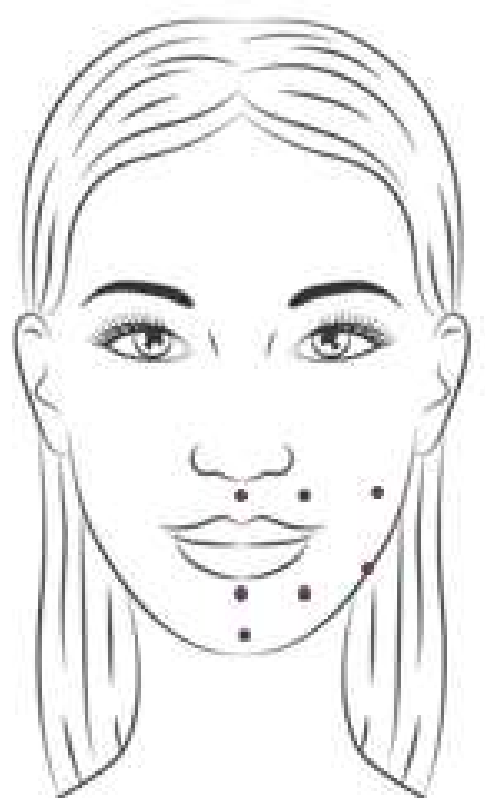

Figura 15 - Esquema da aplicação do LBI de maneira local 


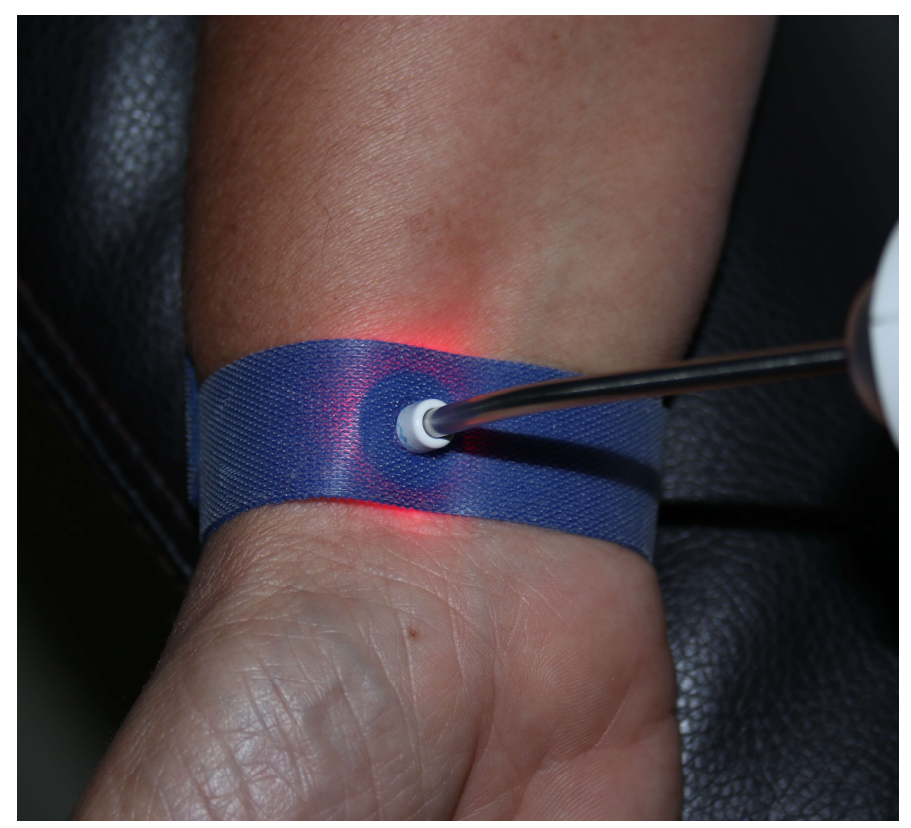

Figura 16 - Aplicação do LBI pelo protocolo ILIB

\subsection{Métodos de avaliação do tratamento}

\subsubsection{Aquisição das imagens 3D utilizando Estereofotogrametria}

O equipamento 3D de estereofotogrametria utilizado foi o Vectra $\mathrm{H} 1$ juntamente com o software Vectra Face Sculptor ${ }^{\circledR}$ (Canfield Scientific, Inc, Fairfield, NJ, EUA). As tomadas fotográficas serão realizadas nos seguintes tempos: TOF - 24 horas no pré-operatório, T1F - 24 horas pós-operatório e T2F - 48 horas pós-operatório.

Para se obter as imagens 3D com o sistema de câmera portátil VECTRA H1 (Figura), o posicionamento do paciente deve ser adequado, e o operador calibrado para realizar as fotografias faciais, o mesmo obterá 3 imagens com alguns segundos de intervalo nas condições específicas sugeridas pelo fabricante: a primeira captura será mantendo a câmera 45 graus para o lado direito do paciente, e aproximadamente 20 a $30 \mathrm{~cm}$ abaixo do rosto do mesmo (Figura 17), a segunda captura deverá ser na posição frontal (Figura 18), e a terceira captura ocorrerá com a câmera 45 graus para o lado esquerdo do paciente, em uma condição similar à primeira captura (Figura 19) (GIBELLI et. al, 2018). Todos os procedimentos serão realizados de acordo com as diretrizes do fabricante e o operador será calibrado para realizar as tomadas fotográficas. 


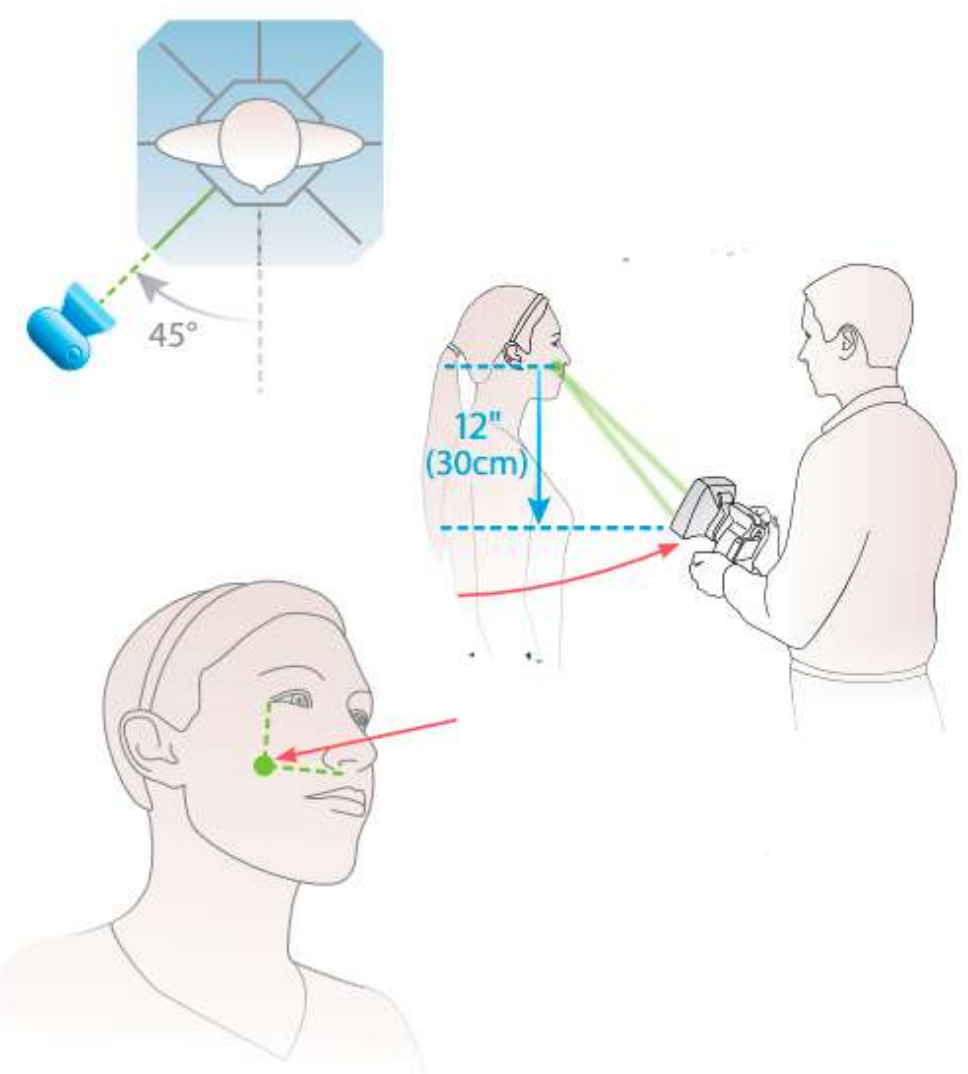

Fonte: Vectra H1 User Guide Software 6.2

Figura 17 - Protocolo de aquisição fotográfica com a câmera posicionada $30 \mathrm{~cm}$ abaixo do rosto do paciente e $45^{\circ}$ a sua esquerda. 


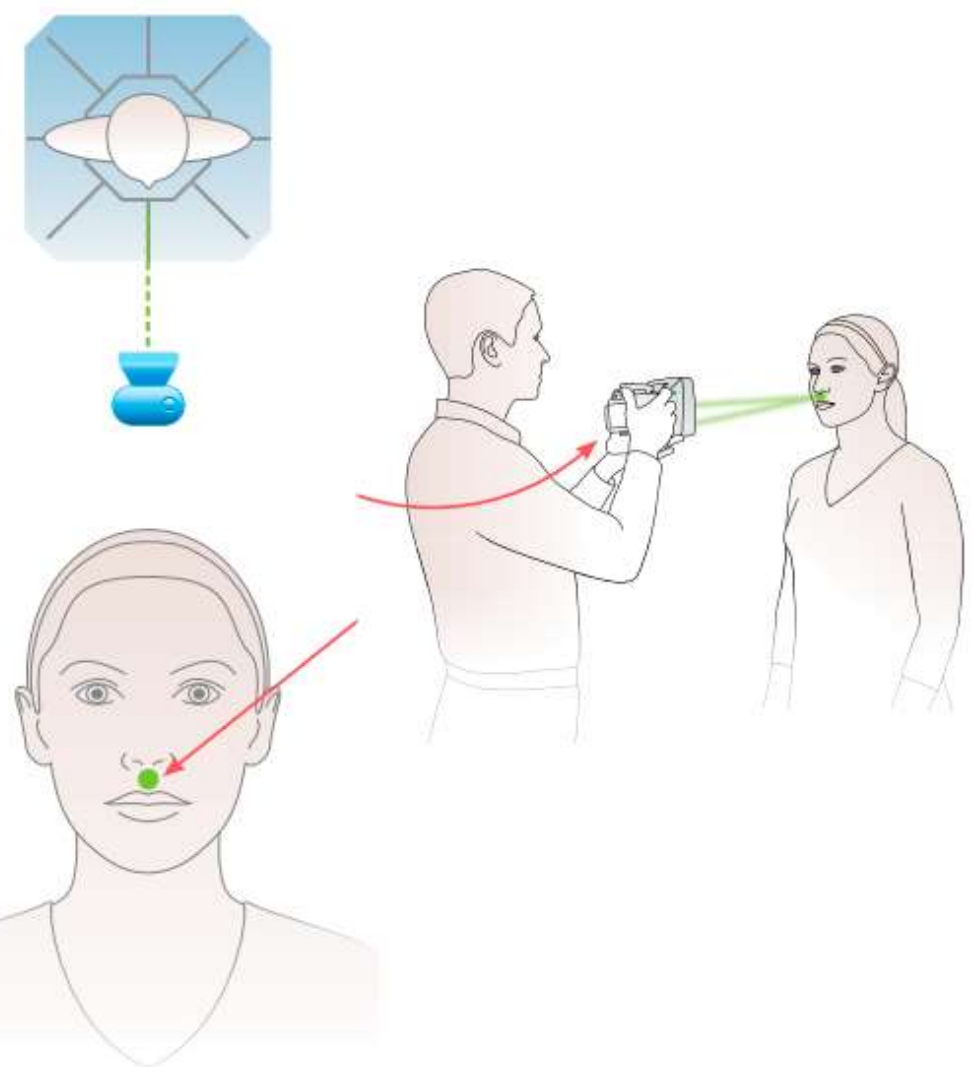

Fonte: Vectra H1 User Guide Software 6.2

Figura 18 - Protocolo de aquisição fotográfica com a câmera posicionada na altura no nariz do paciente e de maneira frontal. 


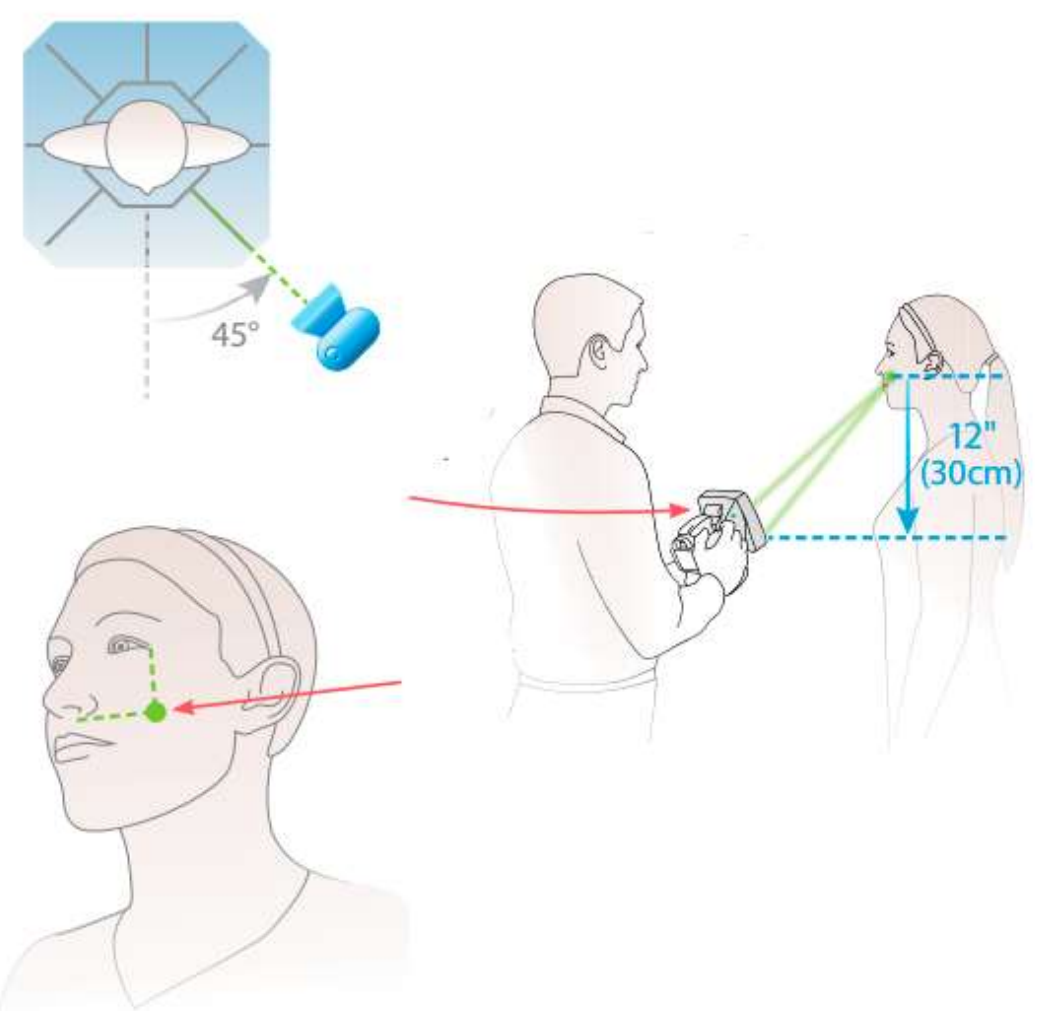

Fonte: Vectra H1 User Guide Software 6.2

Figura 19 - Protocolo de aquisição fotográfica com a câmera posicionada $30 \mathrm{~cm}$ abaixo do rosto do paciente e $45^{\circ}$ a sua direita.

3.3.2 Análise do edema pós-operatório nas imagens 3D utilizando o software Vectra Face Sculptor ${ }^{\circledR}$

A análise do edema pós-operatório foi realizada através da sobreposição das imagens obtidas nos tempos TOF, T1F e T2F no software Vectra Face Sculptor. A diferença volumétrica entre os diferentes períodos de avaliação representa o edema pós-operatório e é dado em mililitros $(\mathrm{ml})$. Para realizar a medição o avaliador se guia pela última delimitação completa obtida pelo padrão de linhas da diferenciação volumetria feita pelo programa (Figura 20 - 25). 


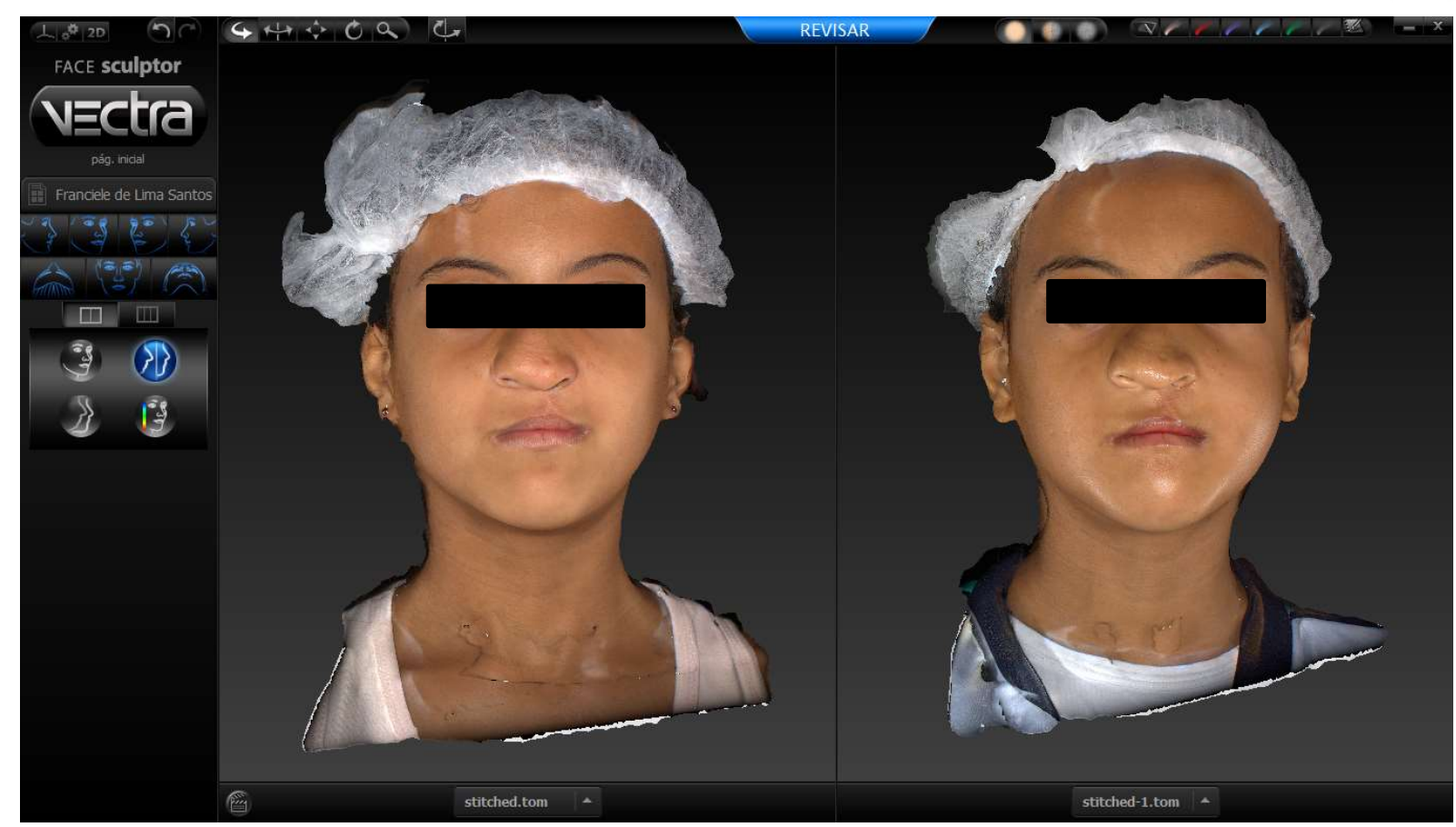

Figura 20 - Imagens do período TOF e T1.

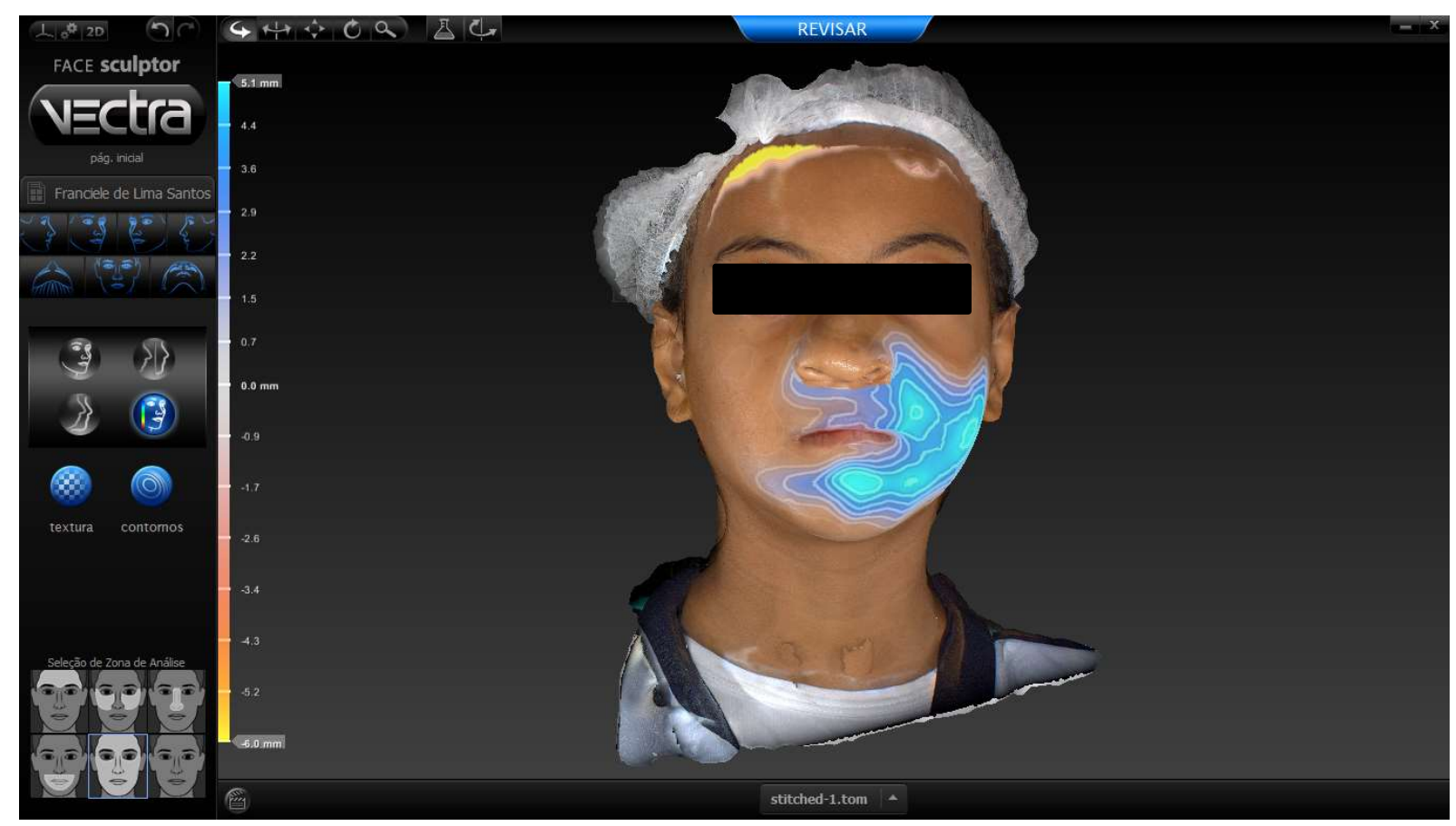

Figura 21 - Sobreposição das imagens evidenciando a alteração de volume. 


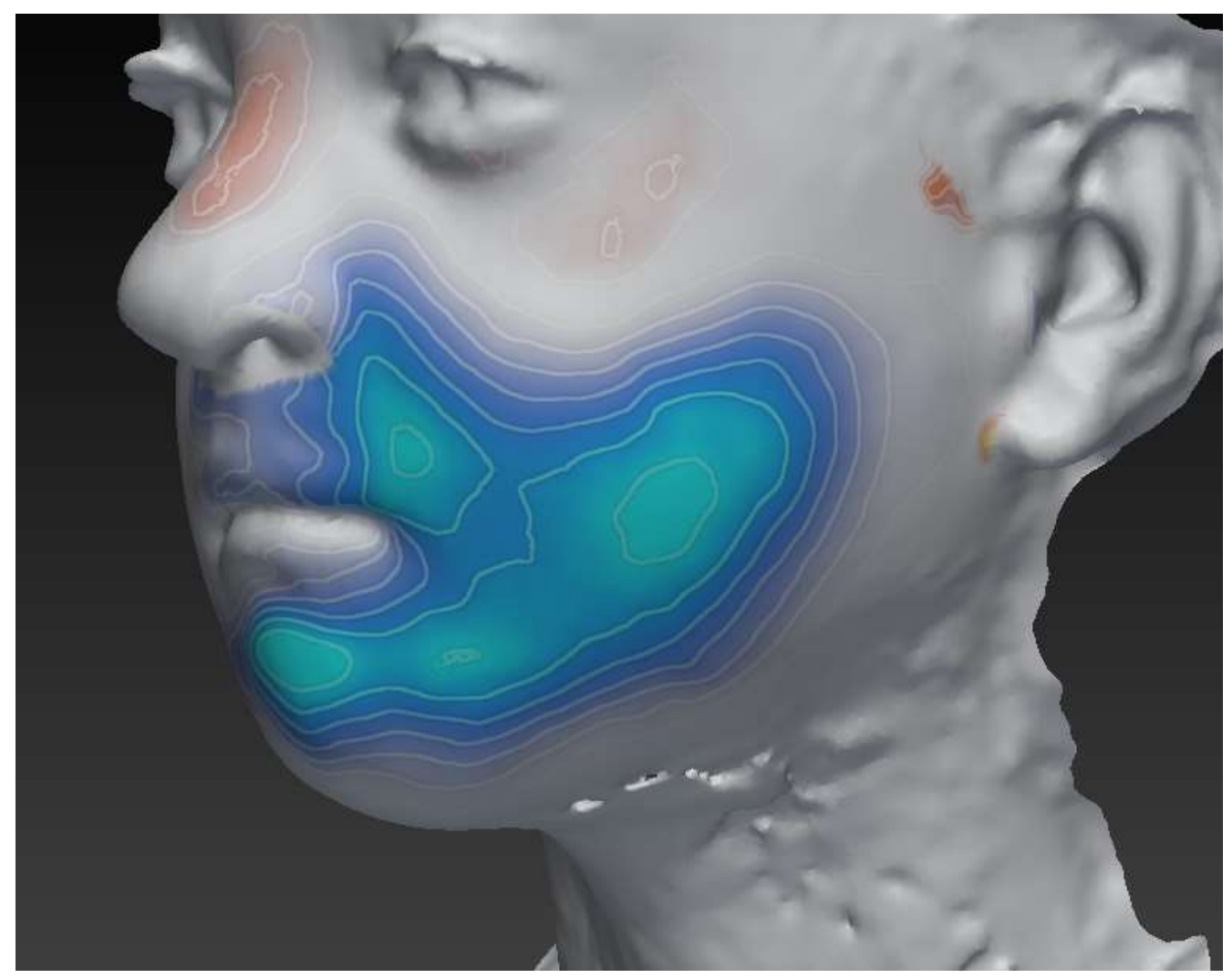

Figura 22 - Padrão de delimitação da diferença volumetria em linhas e cores.

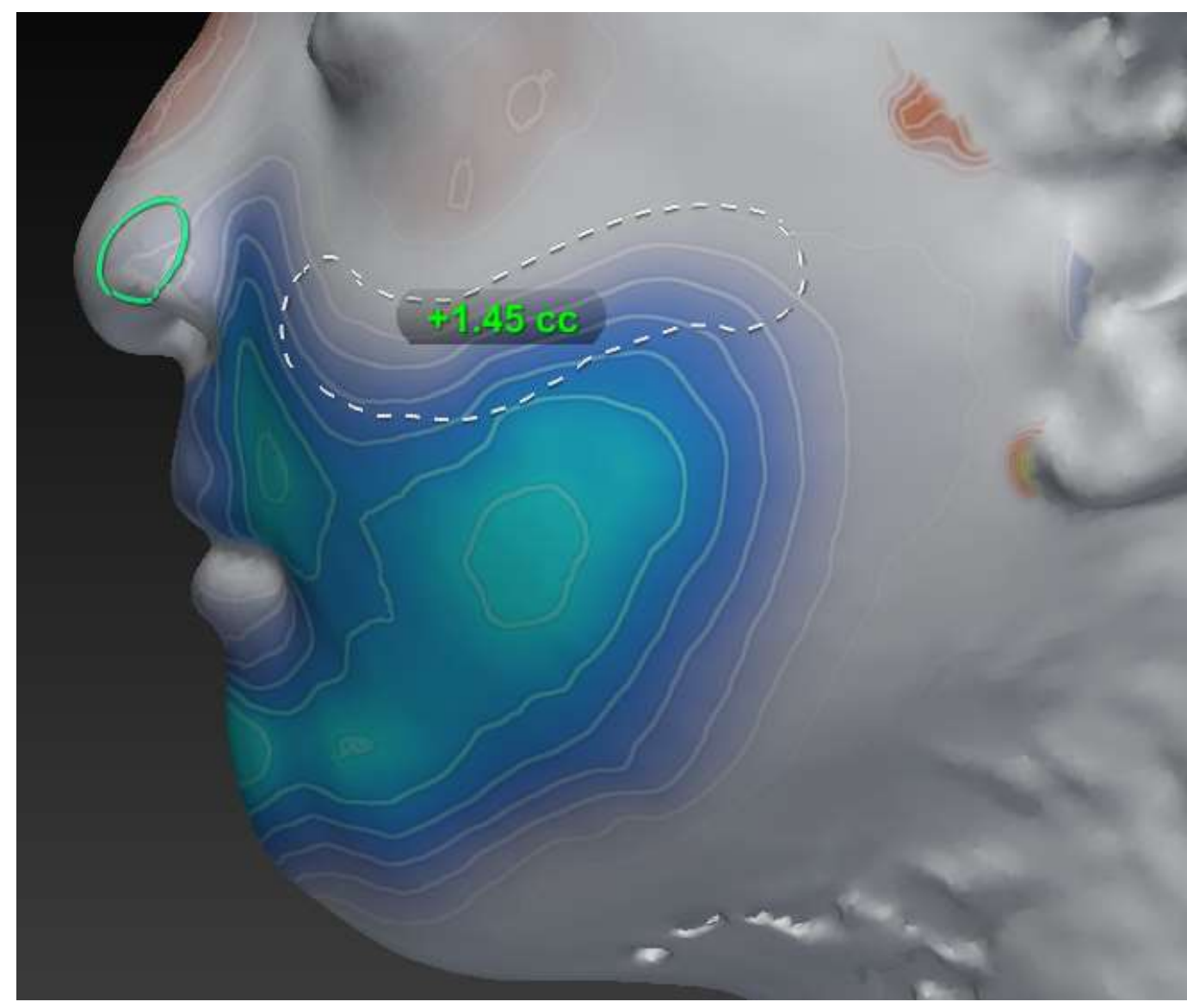

Figura 23 - Delimitação do edema seguindo a última linha completa gerada pelo programa. 


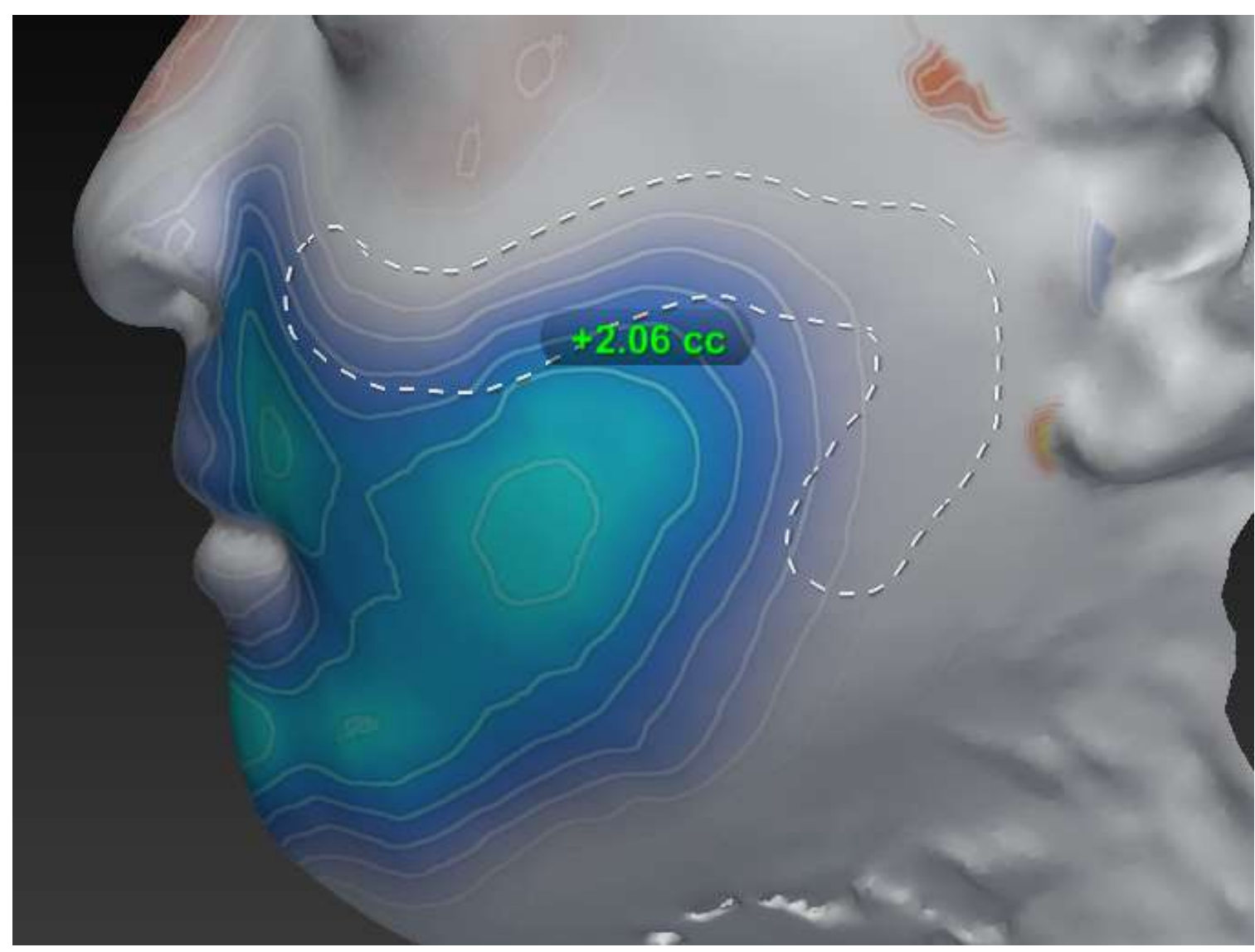

Figura 24 - Delimitação do edema seguindo a última linha completa gerada pelo programa.

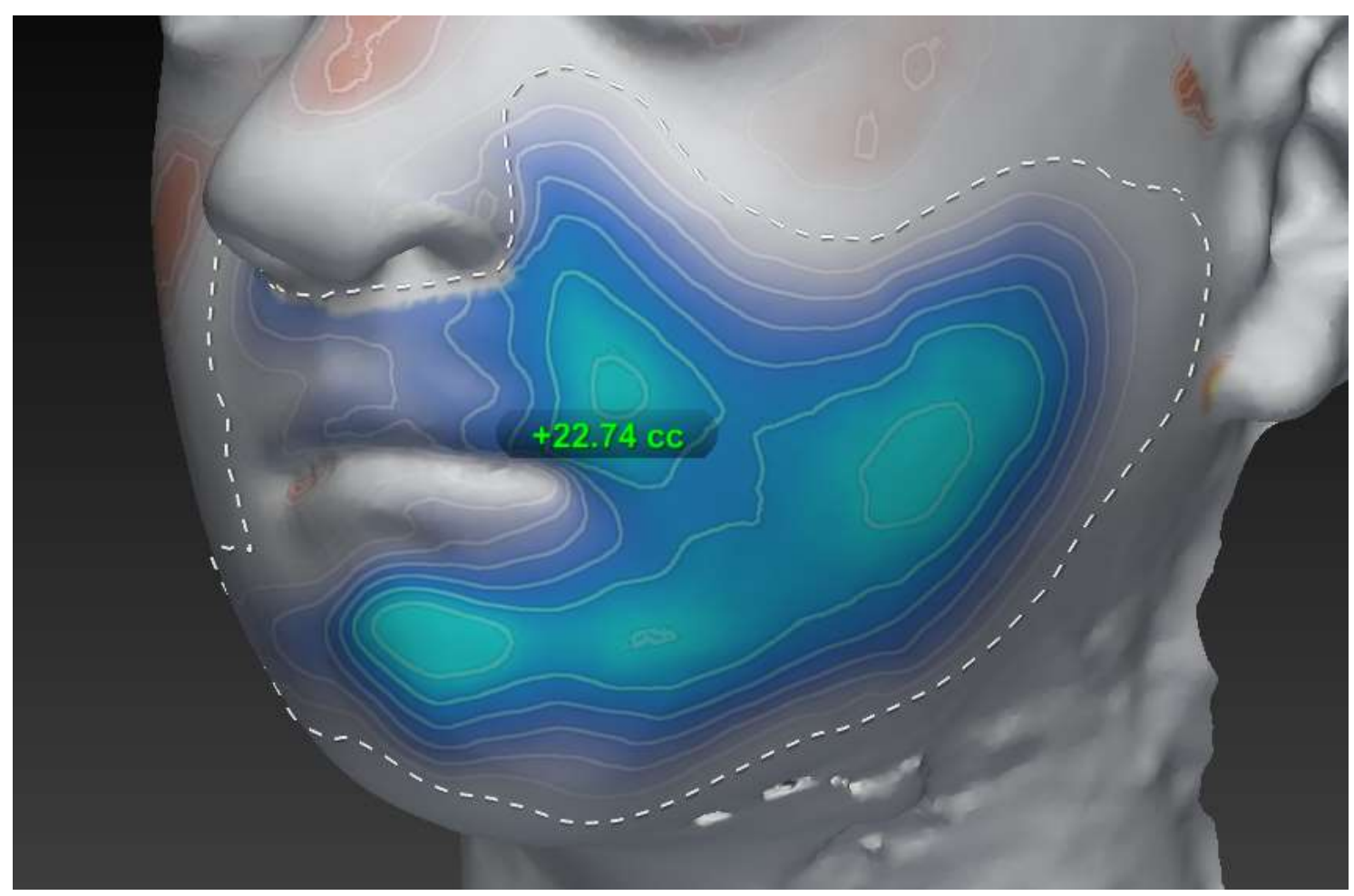

Figura 25 - Medição da diferença volumétrica entre as imagens T0F e T1F. 


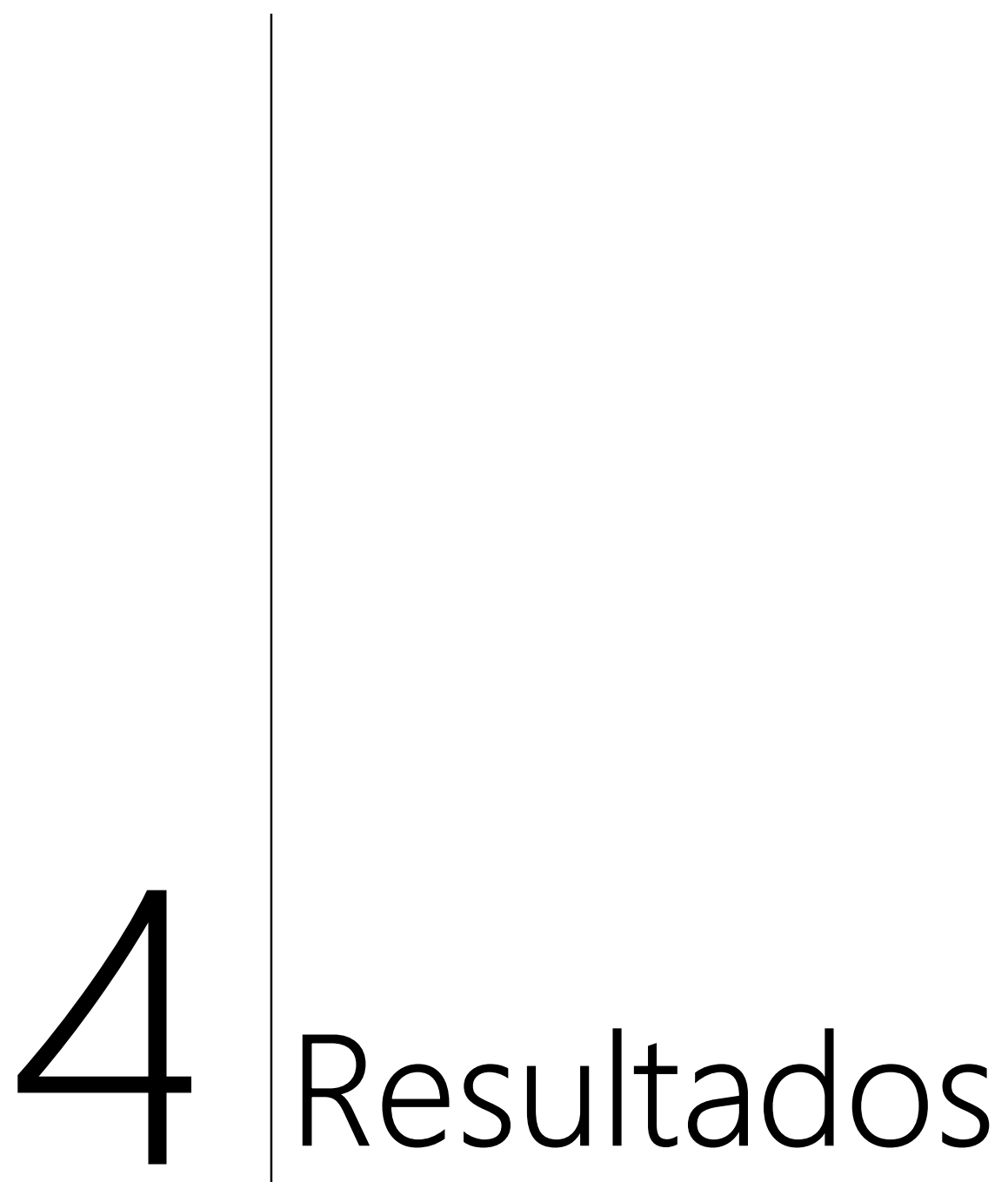





\section{RESULTADOS}

4.1 Avaliação da precisão das medições feitas com o software Face Sculptor Ambos os grupos de cubos gerados digitalmente foram sobrepostos automaticamente pelo programa e em seguida feito a avaliação da diferenciação do volume. Em ambos os casos foi obtido o resultado esperado com total precisão (tabela 1).

Tabela 1 - Avaliação da diferença volumétrica entre os cubos

\begin{tabular}{ccc}
\hline & PAR 1 & PAR 2 \\
\hline Diferença Real de Volume & $25 \mathrm{ml}$ & $0,1 \mathrm{ml}$ \\
Medição & $25 \mathrm{ml}$ & $0,1 \mathrm{ml}$ \\
\hline
\end{tabular}

4.2. Avaliação da precisão da sobreposição automática das fotos no software Face Sculptor

Foram feitas as medições da área determinada em ambos os programas, seguindo a sobreposição automática no software Face Sculptor e manual no software Mirror seguindo os padrões PA, MA e GA. Os dados apresentaram distribuição normal exceto a segunda medição feita no padrão PA, segundo o teste de Shapiro-Wilk.

Os dados que apresentaram distribuição normal foram comparados pelo teste T não pareado, e os dados que não apresentaram normalidade foram comparados pelo teste de Mann Whitney, todos com significância de 5\% ( $p \leq 0,05)$. Para analisar o erro da medição foi realizado o cálculo do erro de Dahlberg. (Tabelas 2 a 11)

Tabela 2 - Medição entre os grupos Sculptor e PA pelo teste T não pareado e o erro de Dahlberg

\begin{tabular}{ccccc} 
& Sculptor & PA & P & ERRO \\
\hline Medição & $4,84 \pm 0,009$ & $5,42 \pm 0,01$ & $<0,0001$ & 0,41 \\
\hline
\end{tabular}

Tabela 3 - Medição entre os grupos Sculptor e MA pelo teste T não pareado e o erro de Dahlberg

\begin{tabular}{ccccc} 
& Sculptor & MA & P & ERRO \\
\hline Medição & $4,84 \pm 0,009$ & $4,69 \pm 0,01$ & $<0,0001$ & 0,11 \\
\hline \multirow{6}{*}{ Tabela 4 - Medição entre os grupos Sculptor e GA pelo teste } & T não pareado e o erro de Dahlberg \\
\hline & Sculptor & GA & P & ERRO \\
\hline Medição & $4,84 \pm 0,009$ & $4,84 \pm 0,01$ & 0,503 & 0,01 \\
\hline
\end{tabular}


Tabela 5 - Segunda medição entre os grupos Sculptor e PA pelo teste Mann Whitney e o erro de Dahlberg

\begin{tabular}{ccccc}
\hline & Sculptor - 2 & PA - 2 & P & ERRO \\
\hline Medição & $4,84 \pm 0,008$ & $5,33 \pm 0,32$ & 0,0014 & 0,41
\end{tabular}

Tabela 6 - Segunda medição entre os grupos Sculptor e MA pelo teste T não pareado e o erro de Dahlberg

\begin{tabular}{ccccc}
\hline & Sculptor - 2 & MA - 2 & P & ERRO \\
\hline Medição & $4,84 \pm 0,008$ & $4,72 \pm 0,01$ & $<0,0001$ & 0,09 \\
\hline
\end{tabular}

Tabela 7 - Segunda medição entre os grupos Sculptor e GA pelo teste T não pareado e o erro de Dahlberg

\begin{tabular}{ccccc}
\hline & Sculptor - 2 & GA - 2 & P & ERRO \\
\hline Medição & $4,84 \pm 0,008$ & $4,84 \pm 0,007$ & 0,93 & 0,01 \\
\hline
\end{tabular}

Tabela 8 - Medição entre os grupos Sculptor em diferentes tempos teste T não pareado e o erro de Dahlberg

\begin{tabular}{ccccc}
\hline & Sculptor & Sculptor - 2 & $\mathbf{P}$ & ERRO \\
\hline Medição & $4,84 \pm 0,009$ & $4,84 \pm 0,008$ & 0,458 & 0,01
\end{tabular}

Tabela 9 - Medição entre os grupos PA em diferentes tempos teste Mann Whitney e o erro de Dahlberg.

\begin{tabular}{ccccc}
\hline & PA & PA - 2 & P & ERRO \\
\hline Medição & $5,42 \pm 0,01$ & $5,33 \pm 0,32$ & 0,305 & 0,23
\end{tabular}

Tabela 10 - Medição entre os grupos MA em diferentes tempos teste T não pareado e o erro de Dahlberg

\begin{tabular}{ccccc}
\hline & MA & MA - 2 & P & ERRO \\
\hline Medição & $4,69 \pm 0,01$ & $4,72 \pm 0,01$ & $<0,0001$ & 0,02 \\
\hline
\end{tabular}

Tabela 11 - Medição entre os grupos GA em diferentes tempos teste T não pareado e o erro de Dahlberg

$\begin{array}{llll}\text { GA } & \text { GA }-2 & \text { P } & \text { ERRO }\end{array}$




Medição $\quad 4,84 \pm 0,01 \quad 4,84 \pm 0,007 \quad 0,605 \quad 0,01$

4.3. Avaliação da acurácia das medições no software Face Sculptor

Os dados referentes a medição das diferentes simulações de edema apresentaram distribuição normal segundo o teste de Shapiro-Wilk. Cada grupo de imagem referente ao mesmo edema foi comparado através do teste T não pareado com significância de $5 \%(p \leq 0,05)$. Para analisar o erro da medição foi realizado o cálculo do erro de Dahlberg (Tabelas 12 a 14).

Tabela 12 - Avaliação da simulação de edema com 1 porção de silicona comparado pelo teste T e o erro de Dahlberg

\begin{tabular}{ccccc}
\hline & Foto 1 & Foto 2 & P & ERRO \\
\hline Medição & $10,02 \pm 0,02$ & $10,02 \pm 0,01$ & 0,681 & 0,02 \\
\hline
\end{tabular}

Tabela 13 - Avaliação da simulação de edema com 2 porções de silicona comparado pelo teste T e o erro de Dahlberg

\begin{tabular}{ccccc}
\hline & Foto 1 & Foto 2 & P & ERRO \\
\hline Medição & $20,3 \pm 0,05$ & $23,33 \pm 0,02$ & 0,108 & 0,04 \\
\hline
\end{tabular}

Tabela 14 - Avaliação da simulação de edema com 3 porções de silicona comparado pelo teste T e o erro de Dahlberg

\begin{tabular}{ccccc}
\hline & Foto 1 & Foto 2 & P & ERRO \\
\hline Medição & $31,81 \pm 0,08$ & $31,83 \pm 0,04$ & 0,616 & 0,08 \\
\hline
\end{tabular}

4.4. Avaliação da reprodutibilidade das medições por diferentes avaliadores.

Os resultados das medições dos indivíduos do grupo piloto, por diferentes avaliadores, apresentaram distribuição normal segundo o teste de Shapiro-Wilk. Os grupos foram comparados através do teste T pareado. com significância de 5\% ( $p \leq$ $0,05)$. Para avaliar a correlação inter e intra-examinador foi calculado o Coeficiente de Correlação Interclasse (ICC) (Tabelas 15 -18).

Tabela 15 - Avaliação da primeira medição do edema por dois avaliadores comparados pelo teste T pareado e ICC

$\begin{array}{llll}1 & 2 & P & \text { ICC }\end{array}$




\begin{tabular}{lrrrr}
\hline Medição & $39,46 \pm 20,91$ & $39,82 \pm 20,70$ & 0,472 & 0,998 \\
\hline
\end{tabular}

Tabela 16 - Avaliação da segunda medição do edema por dois avaliadores comparados pelo teste T pareado e ICC

\begin{tabular}{ccccc}
\hline & 1’ $^{\prime}$ & $\mathbf{2}^{\prime}$ & $\mathbf{P}$ & ICC \\
\hline Medição & $39,18 \pm 20,77$ & $38,38 \pm 20,68$ & 0,326 & 0,996 \\
\hline
\end{tabular}

Tabela 17 - Avaliação das medições do avaliador 1 comparados pelo teste T pareado e ICC

\begin{tabular}{ccccc}
\hline & $\mathbf{1}$ & $\mathbf{1}^{\prime}$ & $\mathbf{P}$ & $\mathbf{I C C}$ \\
\hline Medição & $39,46 \pm 20,91$ & $39,18 \pm 20,77$ & 0,157 & 0,999 \\
\hline
\end{tabular}

Tabela 18 - Avaliação das medições do avaliador 2 comparados pelo teste T pareado e ICC

\begin{tabular}{ccccc}
\hline & $\mathbf{2}$ & $\mathbf{2}^{\prime}$ & $\mathbf{P}$ & ICC \\
\hline Medição & $39,82 \pm 20,70$ & $38,38 \pm 20,68$ & 0,137 & 0,995
\end{tabular}

\subsection{Avaliação do edema pós-operatório}

Inicialmente foram recrutados um total de 27 indivíduos, dos quais sete não atenderam aos critérios de inclusão ou recusaram a participar da pesquisa. $O$ restante foi dividido entre os grupos da pesquisa: grupo 1 (controle) com 6 pacientes, grupo 2 (LBIL) com 8 pacientes e grupo 3 (ILIB) com 6 pacientes.

Os dados referentes a avaliação do edema apresentaram distribuição normal segundo o teste de Shapiro-Wilk exceto no período T2F no grupo 3.

Para comparação dos resultados com distribuição normal obtidos na avaliação do grupo piloto foi usado o teste Ordinary one-way ANOVA, e para avaliação dos grupos sem distribuição normal foi usado o teste Kruskal-Wallis, ambos com significância de $5 \%(p \leq 0,05)$ e estão descritos na tabela 19.

Tabela 19 - Avaliação do edema pós-operatório

\begin{tabular}{ccccc}
\hline & Grupo 1 & Grupo 2 & Grupo 3 & $\mathbf{P}^{*}$ \\
\hline Edema T1F & $39,18 \pm 20,77$ & $44,97 \pm 20,59$ & $40,69 \pm 8,74$ & 0,831 \\
Edema T2F & $48,42 \pm 27,26$ & $48,81 \pm 16,02$ & $55,47 \pm 21,99$ & 0,725 \\
\hline
\end{tabular}




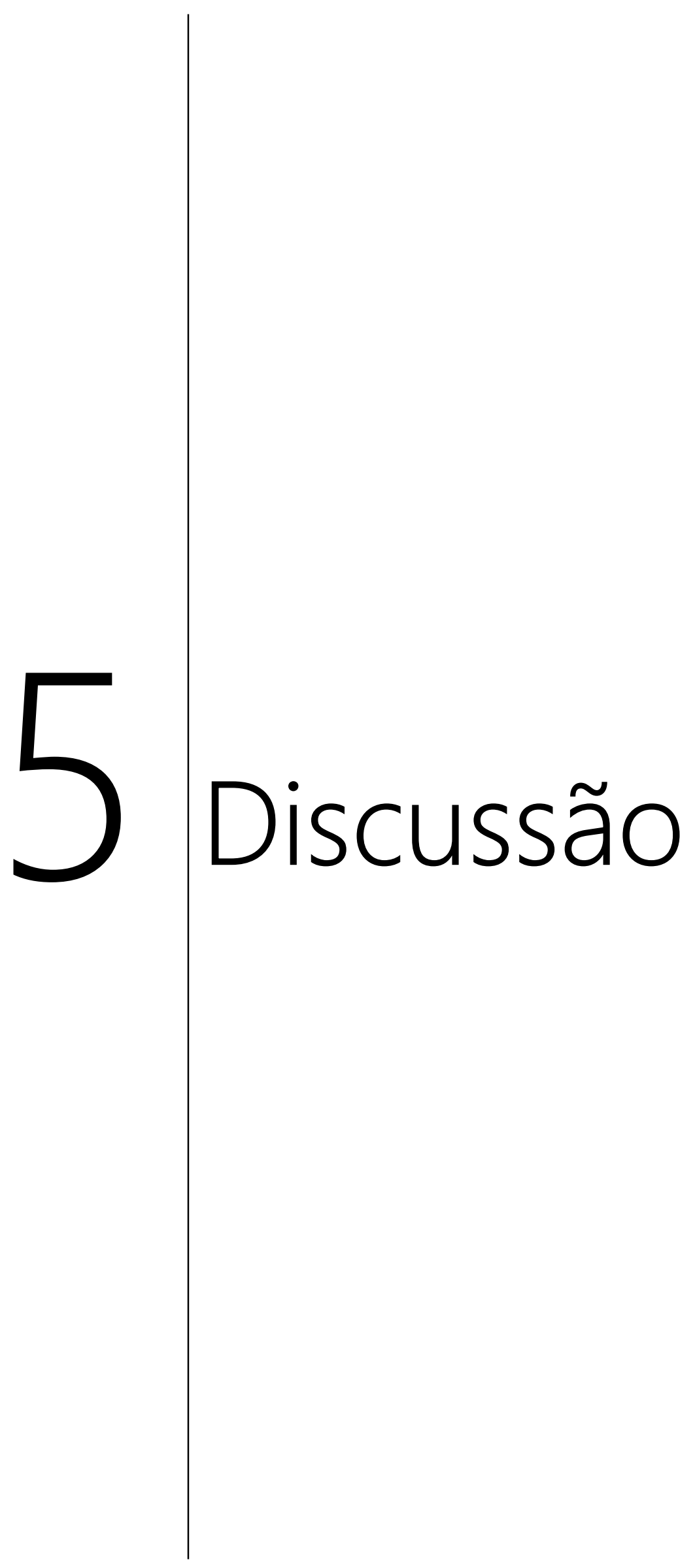





\section{Discussão}

O software Vectra Face Sculptor é válido para realizar medições de diferenciação volumétrica, gerando imagens acuradas e apresentando medições precisas e reproduzíveis. A uso do laser de baixa intensidade, utilizando protocolo de aplicação local ou sistêmico, em cirurgias de rebordo fissurado enxertado com ósseo autógeno não demonstrou efeito antiedematoso quando comparado ao grupo controle

No mercado existem diferentes empresas que produzem produtos para aquisição de imagens em três dimensões (3D) para avaliação das mesmas como: Vectra (Masnada et al. 2020) e 3dMD (Dindaroğlu et al. 2016).

A máquina Vectra $\mathrm{H} 1$ foi utilizada neste estudo para aquisição das imagens em três dimensões, junto do programa Vectra Mirror, que já foi validado para realizar medições lineares (GIBELLI et. al 2018), e também o programa a ser testado Vectra Face Sculptor.

O conjunto Vectra H1 e Vectra Mirror já foi utilizado para realizar análises faciais superfície (GIBELLI et. al 2018) e análises de modelos (Ambrosio et al. 2018). Sua utilização é baseada na avalição da distância e angulação entre diferentes pontos. Para padronização e precisão dos resultados é necessário marcar os pontos anatômicos no rosto do indivíduo antes da tomada fotográfica por um examinador devidamente calibrado.

No presente estudo a realização da marcação dos pontos anatômicos após a realização da cirurgia era dificultada devido o edema e dor no pós-operatório, já que para localizar alguns pontos é necessário a palpação de referências anatômicas.

Mesmo que a utilização da estereofotogrametria para avaliação de diferenciação volumétrica tenha sido proposta para avaliar o edema pós-operatório na face após extrações de terceiros molares (Holland 1979) e tenha sido utilizada para tal finalidade em 1985, essa técnica apresentou grande limitação quanto o posicionamento do paciente, o qual levava a alteração significativa no resultado da avaliação (Pedersen e Maersk-Moller 1985). Em 1996 foi possível avaliar edema oral com estereofotogrametria, diminuindo a variação no posicionamento do paciente com o uso de um cefalostato, diminuindo a limitações existente para sobreposição das imagens (Mocan, Kișnișci e Üçok 1996).

Nos estudos de Holland (1979) e Pedersen e Maersk-Moller (1985) a estereofotogrametria se tratava de um método analógico, as fotografias eram feitas e as coordenadas de pontos de referência eram comparadas em uma sobreposição do 
negativo das imagens. No estudo de Mocan, Kișnișci e Üçok (1996) o uso do cefalostato ajudou na padronização das imagens, resultando assim em uma melhor sobreposição, sendo possível realizar uma comparação. Se tratando de uma tecnologia analógica apresentou limitações semelhante aos estudos anteriores, a sobreposição de pontos de referência era de estruturas subjetivas e a representação topográfica gerada era limitada apenas a esses pontos, o que limita a real avaliação do edema gerado.

Com o avanço da tecnologia as imagens se tornaram digitais e com uma grande definição, aliadas com o avanço da computação, essas imagens são comparadas através de softwares que conferem grande precisão na sobreposição das imagens e nas medições. Ao contrário das tecnologias passadas as imagens geradas são uma representação real do rosto do paciente em 3D deixando de ser apenas uma reprodução de uma área previamente selecionada, conferindo a tecnologia estereofotogramétrica uma precisão mais alta para avaliação e possibilitando uma avaliação integral da diferença entre duas imagens.

A estereofotogrametria para avaliação de edema da face pode apresentar alguns problemas como por exemplo a sobreposição das imagens uma vez que é necessário ter três pontos anatômicos para serem usados como referência, na presença do edema da face pode ocorrer alteração na posição dos pontos anatômicos selecionados, impossibilitando a sobreposição das imagens para realizar a avaliação estereofotogrametricas, uma vez que os pontos anatômicos não coincidiram com a foto pré-operatória (Holland, 1979).

Embora a qualidade das câmeras fotográficas utilizadas para registar as imagens estereofotogrametricas, assim como os programas para costurar e analisar as imagens tenham melhorado significativamente, a limitação que impossibilitou a utilização da técnica no estudo de Holland (1979) também impactou o presente estudo. A utilização da estereofotogrametria com o equipamento Vectra $\mathrm{H} 1$ e o programa Vectra Mirror já foi validado para realizar medições lineares na face (GIBELLI et. al 2018), porém não foi possível sua utilização para avaliar edema na face, com a alteração volumétrica promovida pelo edema os pontos anatômicos mudavam de posição, o que antigamente representou a impossibilidade da sobreposição das imagens, neste estudo representou a impossibilidade de delimitar uma área precisa e reproduzível de avaliação do edema. 
A fim de superar a limitação técnica do programa Vectra Mirror, foi proposto no presente estudo a utilização do programa Vetra Face Sculptor, uma vez que esse programa faz a delimitação automática da área com diferença volumétrica, o que facilita a realização de medições e sua reprodutibilidade. Porém sua utilização ainda não tinha sido validada, tornando-se o objetivo principal desse estudo.

Para avaliação da precisão do programa Vectra Face Sculptor, foi seguido a metodologia apresentada no trabalho de Menezes et al. (2010), com a sobreposição de cubos digitalmente criados com dimensões conhecidas, a fim de avaliar se as medições do programa coincidem com as esperadas ao se sobrepor imagens com tamanhos conhecidos. Nesse caso o programa apresentou resultados esperados com uma avaliação totalmente precisa das sobreposições dos diferentes cubos.

No programa já validado, Vectra Mirror, a sobreposição das imagens era feita manualmente, sendo assim foi necessário avaliar se a sobreposição automática das imagens pelo programa Vectra Face Sculptor era precisa. Para isso, foi comparado a sobreposição automática do programa Face Sculptor com três diferentes sobreposições manuais feitas no Vectra Mirror.

Essa avaliação mostrou, primeiramente, que diferentes extensões das áreas selecionadas geram sobreposições diferentes, ou seja, quanto maior a área selecionada, maior número de pontos anatômicos selecionados, assim como de marcas no rosto do paciente como pintas e cicatrizes, resultando em maior precisão da sobreposição manual no programa Mirror. Quando comparado as sobreposições feitas no Mirror com o Face Sculptor, apenas a sobreposição GA foi estatisticamente significativa. Outro fator que sugere a precisão da sobreposição automática é o erro técnico de mensuração (Teste de Dahlberg), mostrando que as sobreposições PA e MA apresentaram um erro de 0,41 e 0,11 ml, respectivamente, quando comparadas a sobreposição automática, já a sobreposição de GA apresentou um erro de apenas $0,01 \mathrm{ml}$.

Sendo assim a sobreposição automática do software Face Sculptor é precisa e sem diferença estatística à sobreposição com maior detalhamento do programa Mirror, medição essa que leva em consideração maior abrangência da área selecionada e referencias na face do paciente.

Após avaliar a precisão da medição e sobreposição automática das imagens no software foi necessário avaliar a acurácia do sistema em reproduzir imagens 
semelhantes em diferentes tomadas fotográficas, a fim de verificar se diferentes fotografias apresentam o mesmo resultado de diferenciação volumétrica.

Para essa avaliação foram simulados três edemas com volumes diferentes, com uma, duas e três porções de material de moldagem, silicona de condensação e posteriormente foram realizadas as tomadas fotográficas. A fim de se excluir a possibilidade de movimentação do material de moldagem, esse estudo estabeleceu a técnica de posicionamento do material entre os dentes do indivíduo e as tomadas fotográficas foram feitas uma imediatamente após a outra.

$\mathrm{Na}$ avaliação dos diferentes volumes testados, não foi obtida nenhuma diferença estatisticamente significativa entre as duas tomadas fotográficas e o erro técnico de mensuração variou entre $0,02 \mathrm{ml}$ à $0,08 \mathrm{ml}$. Mostrando assim que o sistema Vectra $\mathrm{H} 1$ e o programa Face Sculptor geram imagens acuradas e reproduzível em diferentes tomadas fotográficas.

Por fim, após avaliado que o sistema Vectra H1 e o programa Face Sculptor apresentam medições e realizam sobreposições automáticas precisas, assim como geram imagens acuradas e reproduzíveis, foi feita a avaliação da precisão das medições inter e intra-examinador.

Dois diferentes examinadores avaliaram o edema pós-operatório após a cirurgia de enxerto autógeno na região do rebordo fissurado e repetiram suas medições após uma semana. Os resultados não apresentaram diferença estatisticamente significativa em nenhuma avaliação, mostrando que diferentes avaliações realizadas por um ou mais avaliadores apresentam o mesmo resultado com excelente confiabilidade.

A avaliação do edema pós-operatório não demonstrou diferença estatisticamente significativa sobre o efeito do LBI usado de maneira local ou sistêmica no período pós-operatório de até 48 horas. Embora a utilização sistêmica do laser de baixa intensidade tenha apresentado um maior edema no período de 48 horas após o procedimento cirúrgico com média de 55,47 $\pm 21,99 \mathrm{ml}$, comparado a $48,42 \pm 27,26 \mathrm{ml}$ do grupo controle, resultado que pode ser explicado pela melhora do fluxo sanguíneo e vaso dilatação após o uso sistêmico do LBI (MIKHAYLOV 2015; MOMENZADEH et al. 2015)

Os resultados do presente estudo corroboram com os de outros estudos (Brignardello-Peterson et al., 2012; Cunha et al. 2013; Eroglu; Tunc, 2016; Alan et al. 2016), entretanto os resultados devem ser analisados com cautela. Esse estudo 
apresenta a limitação do número restrito de indivíduos participantes, ou devido a própria complexidade das fissuras de lábio e palato, que podem apresentar diferentes amplitudes e comprometimentos, que possivelmente pode comprometer a morbidade cirúrgica. A metodologia de avaliação do edema ou os protocolos de utilização do LBI também devem ser ponderados.

$\mathrm{Na}$ literatura encontramos diversos protocolos de utilização do LBI com a intenção de diminuição do edema pós-operatório, como por exemplo realizar uma única aplicação de LBI no pós-operatório imediato (Eroglu e Tunc 2016), realizar aplicações imediatamente a cirurgia e também após dois e quatro dias (Eshghpour, Ahari e Talalu 2016) ou a realização de três aplicações seguidas com intervalos de trinta segundos no pós-operatório imediato (Ezzat et al. 2016).

Devido à alta heterogeneidade dos protocolos de utilização do LBI e dos diferentes métodos para avaliação do edema, o desenvolvimento de uma nova metodologia, precisa, para avaliação do edema pode levar a um melhor entendimento do desenvolvimento do edema pós-operatório e os efeitos das diversas terapias sobre essa comorbidade, como o uso do LBI.

Este estudo apresentou limitações quanto a avaliação do edema pósoperatório, relacionadas principalmente quanto a logística dos atendimentos realizados no HRAC. Sendo assim o período de avaliação foi de apenas 48 horas após a cirurgia, o qual representou o pico do edema, caso o período de avaliação tivesse sido maior talvez poderia ter sido observado alguma diferença estatística entre os grupos avaliados.

Outro fator que pode ter contribuído para o resultado do estudo foi a seleção de indivíduos variando entre 9 a 15 anos de idade, uma vez que um indivíduo de 9 anos apresenta um desenvolvimento e estrutura corpórea diferente de um indivíduo de 15 anos (Newell e Wade 2018), o que pode explicar o alto desvio padrão obtido em todos os grupos avaliados no estudo, que variaram entre $8,74 \mathrm{ml} \mathrm{e} 27,26 \mathrm{ml}$. Novamente, essa faixa de etária foi estabelecida levando em conta o fluxo de pacientes atendidos pelo HRAC, sendo essa, a faixa etária que compreende o maior número de pacientes que são submetidos a cirurgia de enxerto ósseo na região da fissura. 

6 conclusão 



\section{CONCLUSÕES}

Baseado nos resultados obtidos nesse estudo conclui-se que:

- O software Vectra Face Sculptor é valido para realizar medições de diferenciação volumétrica, gerando imagens acuradas e apresentando medições precisas e reproduzíveis.

- A uso do laser de baixa intensidade, utilizando protocolo de aplicação local ou sistêmico, em cirurgias de rebordo fissurado enxertado ósseo autógeno, não apresentaram resultados estatisticamente diferentes quando comparado ao grupo controle, sendo necessário a realização de um estudo clínico randomizado. 

Referências 



\section{REFERÊNCIAS}

1. Shaw SP, J Wingfield, M J Dorsey, J Ma Mol Cell Biol. 1996;16(7): 3651-3657.

2. Wilcox AJ, Lie RT, Solvoll K, Taylor J, McConnaughey DR, Abyholm F, et al. Folic acid supplements and risk of facial clefts: national population based case-control study. BMJ 2017;334:464. 10.1136/bmj.39079.618287.0B.

3. Freitas JAS, Neves LT, Almeida ALPF, Garib, DG, Trindade-Suedam IK, Yaedú RYF, et al. Rehabilitative treatment of cleft lip and palate: experience of the Hospital for Rehabilitation of Craniofacial Anomalies - USP (HRAC/USP) - Part 1: Overall Aspects. J Appl Oral Sci. 2012a;20:9-15.

4. World Health Organization. Global strategies to reduce the heath-care burden of craniofacial anomalies. Genebra: WHO; 2002

5. Dalben GS. Prevalência dos tipos de fissuras lábio-palatais entre pacientes não operados - Levantamento realizado no ano 2000. [Monografia]. Bauru (SP): Hospital de Pesquisa e Reabilitação de Lesões Lábio-palatias, Universidade de São Paulo, 2002.

6. Freitas JA, Dalben GS, Santamaria Jr M, Freitas PZ. Current data on the characterization of oral clefts in Brazil. Braz Oral Res. 2005;18:128-133.

7. Silva Filho OG, Freitas JAS. Caracterização morfológica e origem embriológica. In: Trindade IEK, Silva Filho OG, Fissuras labiopalatinas. Uma abordagem interdisciplinar. São Paulo: Livraria Santos Editora: 2007. p.17-49.

8. Freitas JAS, Almeida ALPF, Soares S, Garib DG, Lauris RC, Neves LT, et al. Rehabilitative treatment of cleft lip and palate: experience of the Hospital for Rehabilitation of Craniofacial Anomalies - USP (HRAC/USP) - Part 4: Oral Rehabilitation. J Appl Oral Sci. 2013;21:284-292

9. Freitas JAS, Garib DG, Vallarelli TM, Almeida ALPF, Trindade-Suedam IK, Neves LT et al. Rehabilitative treatment of cleft lip and palate: experience of the Hospital for Rehabilitation of Craniofacial Anomalies - USP (HRAC/USP) - Part 2: Pediatric Dentistry and Orthodontics. J Appl Oral Sci. 2012b;20:272-285

10. Freitas JAS, Almeida ALPF, Soares S, Garib DG, Lauris RC, Neves LT, et al. Rehabilitative treatment of cleft lip and palate: experience of the Hospital for Rehabilitation of Craniofacial Anomalies - USP (HRAC/USP) - Part 3: Oral and Maxillofacial Surgery. J Appl Oral Sci. 2012c;20:673-679. 
11. Wu, C, Pan, W, Feng, C, Su, Z, Duan, Z, Zheng, Q, Li, C. Grafting materials for alveolar cleft reconstruction: a systematic review and best-evidence synthesis. International Journal of Oral and Maxillofacial Surgery, 2018;47(3):345-356.

12. Hallman $M$, Thor $A$. Bone substitutes and growth factors as an alternative/complement to autogenous bone for grafting in implant dentistry. Periodontol 2000. 2008;47:172-192.

13. Saygun I, Karacay S, Serdar M, Ural AU, Sencimen M, Kurtis B. Effects of laser irradiation on the release of basic fibroblast growth factor (bFGF), insulin like growth factor-1 (IGF-1), and receptor of IGF-1 (IGFBP3) from gingival fibroblasts. Lasers Med Sci. 2008;23(2):211-215. doi:10.1007/s10103-007-0477-3

14. Almeida, ALPF; Medeiros, IL; Cunha, MJS.; Sbrana, MC; Oliveira, PGFP; Esper, LA. The effect of low-level laser on bone healing in critical size defects treated with or without autogenous bone graft: an experimental study in rat calvaria. Clinical Oral Implants Research, v. 25, p. 1131-1136, 2014

15. Cunha, MJS et al. Effect of Low-Level Laser on Bone Defects Treated with Bovine or Autogenous Bone Grafts: In Vivo Study in Rat Calvaria. BioMed research international. 2014;1-9

16. Freitas NR, Guerrini LB, Esper LA, Sbrana MC, Dalben GS, Soares S, Almeida ALPF. Evaluation of photobiomodulation therapy associated with guided bone regeneration in critical size defects. In vivo study. J Appl Oral Sci. 2018; 26:e20170244. 17. Fujihara NA, Hikari KR, Marques MM. Irradiation at $780 \mathrm{~nm}$ increases proliferation rate os osteoblastos independently of dexamethasone presence. Lasers Surg Med. 2006;38:332-336.

18. Moskvin SV. Low-level laser therapy in Russia: history, science and practice. J Lasers Med Sci. 2017;8(2):56-65.

19. Carroll JD, Milward MR, Cooper PR, Hadis M, Palin WM. Developments in low level light therapy (LLLT) for dentistry. 2014;0:465-75.

20. Carvalho R, Coelho P, Prates L, Zerbinati S. Systemic effects of LLLT on bone repair around PLLA - PGA screws in the rabbit tibia. 2014;703-8.

21. Rodrigo SM, Cunha A, Pozza DH, Blaya DS. Analysis of the Systemic Effect of Red. 2009;27(6):929-35.

22. Mikhaylov V. The use of Intravenous Laser Blood Irradiation ( ILBI ) at 630-640 nm to prevent vascular diseases and. Laser Ther. 2015;15-26 
23. Momenzadeh S, Abbasi M, Ebadifar A, Aryani M. The Intravenous Laser Blood Irradiation in Chronic Pain and Fibromyalgia. 2015;6(1):6-9.

24. Lewandrowski K, Gresser JD, Wise DL, Trantolo DJ. Bioresorbable bone graft substitutes of di ! erent osteoconductivities : a histologic evaluation of osteointegration of poly ( propylene glycol-co-fumaric acid ) -based cement implants in rats. 2000;21:757-64

25. Grado GF De, Keller L, Idoux-gillet Y, Wagner Q, Musset A, Benkirane-jessel N, et al. Bone substitutes : a review of their characteristics, clinical use, and perspectives for large bone defects management. 2018; J Tissue Eng. 2018;9:2041731418776819 26. Aghaloo TL, Hadaya D. Basic Principles of Bioengineering and Regeneration. Oral Maxillofac Surg Clin NA [Internet]. 2017;29(1):1-7.

27. Giannoudis PV, Dinopoulos H, Tsiridis E. Bone substitutes: An update. Injury, 2005;36(3), S20-S27.

28. Bosco A, Lazilha P, Rodrigues L, Gouveia V, Helena L, Januario N, et al. Journal of Photochemistry \& Photobiology, B : Biology Effects of low-level laser therapy on bone healing of critical-size defects treated with bovine bone graft. JPB [Internet]. 2016;163:303-10.

29. Pyo S, Song W, Kim I, Park B, Kim C, Shin S. Low-level laser therapy induces the expressions of BMP-2, osteocalcin , and TGF- $\beta 1$ in hypoxic-cultured human osteoblasts. 2013;543-50

30. Saghiri M, Asatourian A, Garcia-godoy F, Sheibani N. The role of angiogenesis in implant dentistry part II: The effect of bone-grafting and barrier membrane materials on angiogenesis. Med Oral Patol Oral Cir Bucal. 2016;21(4):e526-37.

31. Tim CR, Bossini PS, Kido HW, et al. Effects of low level laser therapy on inflammatory and angiogenic gene expression during the process of bone healing: $A$ microarray analysis. J Photochem Photobiol B. 2016;154:8-15. doi:10.1016/j.jphotobiol.2015.10.028

32. Cunha, MJS et al. Evaluation of the effectiveness of diode laser on pain and edema in individuals with cleft lip and palate submitted to secundar bone graft. Cleft Palate J. 2013;50:e92-e97

33. Piso DU, Eckardt A, Liebermann A, Gutenbrunner C, Schäfer P, Gehrke A. Early rehabilitation of head-neck edema after curative surgery for orofacial tumors. Am J Phys Med Rehabil. 2001;80(4):261-269. doi:10.1097/00002060-200104000-00006 
34. de Menezes M, Rosati R, Allievi C, Sforza C. A photographic system for the threedimensional study of facial morphology. Angle Orthod. 2009 Nov;79(6):1070-7. doi: 10.2319/111008-570

35. Rosati R, De Menezes M, da Silva AM, Rossetti A, Lanza Attisano GC, Sforza C. Stereophotogrammetric evaluation of tooth-induced labial protrusion. J Prosthodont. 2014;23(5):347-52

36. Camison L, Bykowski M, Lee WW, Carlson JC, Roosenboom J, Goldstein JA, Losee JE, Weinberg SM. Validation of the Vectra H1 portable three-dimensional photogrammetry system for facial imaging. Int J Oral Maxillofac Surg. 2018;47(3):403410

37. Gibelli D, Pucciarelli V, Poppa P, Cummaudo M, Dolci C, Cattaneo C, Sforza C. Three-dimensional facial anatomy evaluation: Reliability of laser scanner consecutive scans procedure in comparison with stereophotogrammetry. J Craniomaxillofacial Surg. 2018;S1010-5182(18)30563-8.

38. Van der Vlis M, Dentino KM, Vervloet B, Padwa BL. Postoperative Swelling After Orthognathic Surgery: A Prospective Volumetric Analysis. Journal of Oral and Maxillofacial Surgery, 2014;72(11): 2241-2247

39. van der Meer WJ, Dijkstra PU, Visser A, Vissink A, Ren Y. Reliability and validity of measurements of facial swelling with a stereophotogrammetry optical threedimensional scanner. $\mathrm{Br} J$ Oral Maxillofac Surg. 2014;52(10):922-927. doi:10.1016/j.bjoms.2014.08.019

40. Masnada S, Gibelli D, Dolci C, et al. 3D facial morphometry in Italian patients affected by Aicardi syndrome. Am J Med Genet A. 2020;182(10):2325-2332 doi:10.1002/ajmg.a.61791

41. Dindaroğlu F, Kutlu P, Duran GS, Görgülü S, Aslan E. Accuracy and reliability of 3D stereophotogrammetry: A comparison to direct anthropometry and 2D photogrammetry. Angle Orthod. 2016;86(3):487-494. doi:10.2319/041415-244.1

42. Ambrosio ECP, Sforza C, De Menezes M, et al. Longitudinal morphometric analysis of dental arch of children with cleft lip and palate: 3D stereophotogrammetry study. Oral Surg Oral Med Oral Pathol Oral Radiol. 2018;126(6):463-468. doi:10.1016/j.00oo.2018.08.012

43. Holland CS. The development of a method of assessing swelling following third molar surgery. $\mathrm{Br} J$ Oral Surg. 1979;17(2):104-114. doi:10.1016/s0007$117 \times(79) 80037-2$ 
44. Pedersen A, Maersk-Møller O. Volumetric determination of extraoral swelling from stereophotographs. A method study in the buccal area. Int $\mathrm{J}$ Oral Surg. 1985;14(3):229-234. doi:10.1016/s0300-9785(85)80033-8

45. Mocan A, Kişnişci R, Uçok C. Stereophotogrammetric and clinical evaluation of morbidity after removal of lower third molars by two different surgical techniques. J Oral Maxillofac Surg. 1996;54(2):171-175. doi:10.1016/s0278-2391(96)90441-3

46. de Menezes M, Rosati R, Ferrario VF, Sforza C. Accuracy and reproducibility of a 3-dimensional stereophotogrammetric imaging system. J Oral Maxillofac Surg. 2010;68(9):2129-2135. doi:10.1016/j.joms.2009.09.036

47. Brignardello-Petersen R, Carrasco-Labra A, Araya I, Yanine N, Beyene J, Shah PS. Is adjuvant laser therapy effective for preventing pain, swelling, and trismus after surgical removal of impacted mandibular third molars? A systematic review and metaanalysis. J Oral Maxillofac Surg. 2012;70(8):1789-1801. doi:10.1016/j.joms.2012.01.008

48. Eroglu CN, Keskin Tunc S. Effectiveness of Single Session of Low-Level Laser Therapy with a $940 \mathrm{~nm}$ Wavelength Diode Laser on Pain, Swelling, and Trismus After Impacted Third Molar Surgery. Photomed Laser Surg. 2016;34(9):406-410. doi:10.1089/pho.2016.4101

49. Alan H, Yolcu Ü, Koparal M, Özgür C, Öztürk SA, Malkoç S. Evaluation of the effects of the low-level laser therapy on swelling, pain, and trismus after removal of impacted lower third molar. Head Face Med. 2016;12(1):25. Published 2016 Jul 26. doi:10.1186/s13005-016-0121-1

50. Eshghpour M, Ahrari F, Takallu M. Is Low-Level Laser Therapy Effective in the Management of Pain and Swelling After Mandibular Third Molar Surgery?. J Oral Maxillofac Surg. 2016;74(7):1322.e1-1322.e13228. doi:10.1016/j.joms.2016.02.030 51. Ezzat AE, El-Shenawy HM, El-Begermy MM, Eid MI, Akel MM, Abbas AY. The effectiveness of low-level laser on postoperative pain and edema in secondary palatal operation. Int J Pediatr Otorhinolaryngol. 2016;89:183-186. doi:10.1016/j.ijporl.2016.07.038

52. Newell KM, Wade MG. Physical Growth, Body Scale, and Perceptual-Motor Development. Adv Child Dev Behav. 2018;55:205-243. doi:10.1016/bs.acdb.2018.04.005 

Anexos 

ANEXOS

\section{Anexo 1 Termo de Assentimento Livre e Esclarecido}

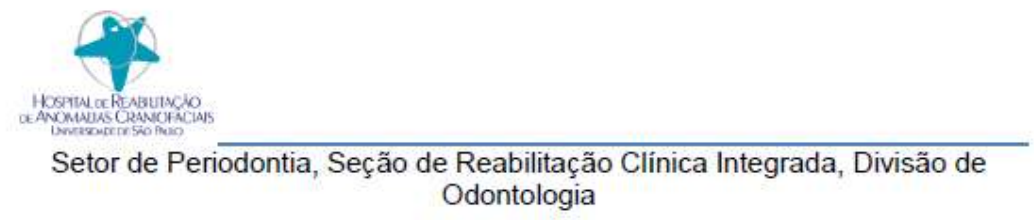

TERMO DE ASSENTIMENTO LIVRE E ESCLARECIDO

Eu sou Pedro Henrique Hernandes Job, faço parte da equipe de pesquisa da Profa. Dra. Ana Lucia Pompeia Fraga De Almeida, daqui do Centrinho. Estamos pesquisando o efeito da luz (laser de baixa intensidade) nos enxertos ósseos nas fissuras.

Estamos te convidando a fazer parte, como voluntário, desta pesquisa. Já conversamos com seus responsáveis que aceitaram fazer parte, mas se você não quiser, você não precisa participar e em nada vai mudar no seu tratamento se você não quiser participar. Caso queira, você pode conversar com alguém antes de decidir se quer participar ou não.

Temos como objetivo desta pesquisa estudar o papel da luz na cirurgia de enxerto ósseo na região da fissura. Essa cirurgia pode causar desconfortos como dor e inchaço, nossa intenção é avaliar através de fotos e perguntas a função da luz para diminuir a dor e o inchaço.

Por você apresentar fissura e estar indicado a cirurgia de enxerto ósseo, te escolhemos para participar desta pesquisa. Mesmo que você aceite fazer parte da pesquisa e em algum momento decida em parar de participar não tem nenhum problema, nada vai mudar no seu tratamento ou na sua relação as pessoas que estão tradando de você.

No inicio da pesquisa vamos avaliar a saúde de sua boca, um procedimento simples no qual medimos sua gengiva com uma régua odontológica. Depois disso vamos sortear para ver em qual grupo da pesquisa você vai participar: um grupo não vamos aplicar a luz, no outro vamos aplicar a luz na região da fissura, e o ultimo grupo vamos aplicar a luz na região do seu pulso. A aplicação da luz na região da fissura leva em torno de cinco minutos, já no pulso leva trinta minutos. Essas aplicações vão ocorrer nesta primeira consulta junto da avaliação da saúde de sua boca e as outras imediatamente

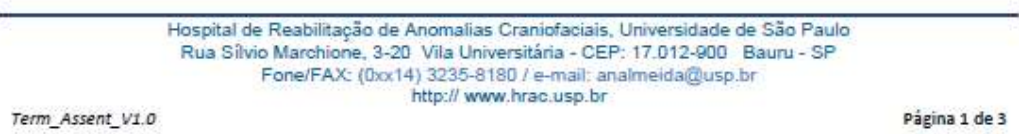




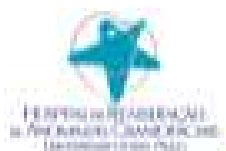

Setor de Periodontia, Seçăo de Reabilitaçāo Clínica Integrada, Divisáo de Odontologia

consulta junto da avaliação da saúde de sua boca e as outras imediatamente após a cirurgia e um dia após a cirurgia. Para medir se a luz ajudou a diminuir a dor e o inchaço vamos fazer perguntas sobre a quantidade de dor que você está sentindo de zero a dez, e tirar uma sequéncia de trés fotos, no dia antes da cirurgia, imediatamente após a cirurgia, e nos próximos dois dias.

0 procedimento para avaliar a saúde de sua boca pode trazer algum desconforto pois a gengiva é delicada. A aplicação da luz é segura, porem não pode visualizar a luz diretamente, sendo assim, sempre que fomos aplicar a luz vocé estará usando óculos de proteçäo, fora isso por chegar a demorar até trinca minutos o procedimento poderá ser um pouco cansativo.

A luz melhora a cicatrizaçäo das cirurgias, com essa pesquisa vamos entender a sua funçăo para diminuir a dor e principalmente para diminuir o inchaço, assim melhorando o tratamento dos pacientes dos centros de saúde, assim como o do Centrinho.

Suas informações coletadas na pesquisa e ninguém exceto os investigadores poderăo ter acesso a elas, nảo falaremos que você está na pesquisa com mais ninguém e seu nome nảo aparecerá em nenhum lugar. Depois que a pesquisa acabar, os resultados seräo informados para vocè e seus pais, também poderá ser publicada em uma revista, ou livro, ou conferência, etc.

Lembrando que vocè pode escolher para de fazer parte de pesquisa a qualquer momento e ninguém vai ficar desapontado ou chateado por isso. A escolha é sua. Vocé pode pensar nisto e falar depois se wocè quiser. Você pode dizer sim agora e mudar de ideia depois e tudo continuará bem.

Caso queira conversar mais sobre a pesquisa vocé pode vir falar comigo Pedro Henrique Hernandes Job ou a Professora Ana Lucia Pompeia Fraga De Almeida, estaremos sempre à disposiçäo.

\begin{tabular}{|c|c|}
\hline & 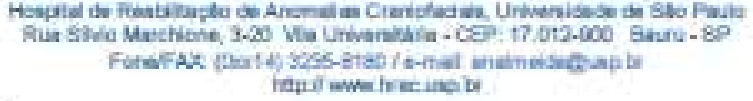 \\
\hline Asene via & \\
\hline
\end{tabular}




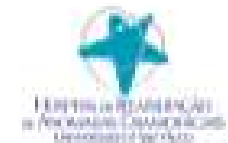

Setor de Periodontia, Seçáo de Reabilitaçáo Clinica Integrada, Divisáo de Odontologia

Acompanhei a explicação que foi feita à criança/adolescente sobre a pesquisa: "Efeito do laser sistèmico ou pontual em área de rebordo alveolar fissurado enxertado com osso autógeno. Análise por estereofotogrametria" e o(a) mesmo(a) concordou em participar.

Assinatura dos pais/responsáveis:

Assinatura do pesquisador:

Data:

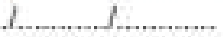


Anexo 2 - Parecer Consubstanciado do CEP

USP - HOSPITAL DE
REABILITAÇÃO DE
ANOMALIAS CRANIOFACIAIS

\section{PARECER CONSUBSTANCIADO DO CEP}

\section{DADOS DO PROJETO DE PESQUISA}

Título da Pesquisa: Efeito do laser sistêmico ou pontual em área de rebordo alveolar fissurado enxertado com osso autógeno. Análise por estereofotogrametria

Pesquisador: Ana Lúcia Pompéia Fraga de Almeida

Área Temática:

Versão: 2

CAAE: 01436618.4 .0000 .5441

Instituição Proponente: Hospital de Reabilitação de Anomalias Craniofaciais da USP

Patrocinador Principal: Financiamento Próprio

\section{DADOS DO PARECER}

Número do Parecer: 3.046 .783

Apresentação do Projeto:

Pesquisa clinica e longitudinal sobre o efeito do laser sistêmico ou pontual em área de rebordo alveolar fissurado enxertado com osso autógeno, por estereofotogrametria. Trata-se de um estudo constituido de 45 individuos com fissura de lábio e palato de 9 a 15 anos de ambos os sexos.

Objetivo da Pesquisa:

Avaliar se existe diferença na utilização do laser sistêmico ou pontual nas cirurgias de enxerto ósseo em fissura lábio palatina.

Avaliação dos Riscos e Beneficios:

A aplicação do laser de baixa intensidade quando direcionada ao olho do paciente pode trazer danos a sua visão, por esse motivo durante toda aplicação do laser de baixa intensidade o paciente usa um óculos de proteção, fora isso, sua aplicação varia entre cinco a trinta minutos, o que pode se caracterizar como desconforto para ao paciente. $O$ exame para avaliar a saúde oral não causa nenhum risco a saúde do paciente, mas pode haver um leve desconforto durante a medição da profundidade de sondagem, por se tratar de uma área delicada. A análise de estereofotogrametria é baseado no registro de três fotografias, que quando processados no software Vectra Face Sculptor @ gera uma imagem 3D, evidenciando o relevo do rosto do paciente, através do qual ele ainda pode ser identificado.

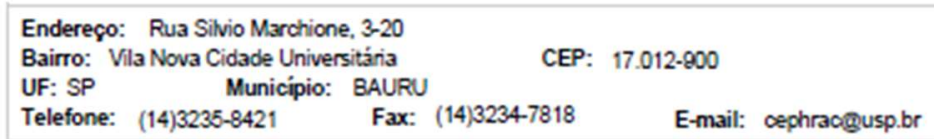




\section{USP - HOSPITAL DE REABILITAÇÃO DE ANOMALIAS CRANIOFACIAIS}

Conthuaç50 do Parecer. 3.046 .783

A utilização do laser de baixa intensidade associado a enxertos ósseos mostra resultados promissores, na diminuição do edema e dor pós-operatória, na melhora da formação óssea e na melhora da cicatrização. 0 maior entendimento de sua atuação, através de um método de avaliação preciso e pouco invasivo, se mostra de grande importância para, podendo melhorar o tratamento cirúrgico realizados nos pacientes com fissura de lábio e palato

Comentários e Considerações sobre a Pesquisa:

Pesquisa com mérito científico.

Consideraçōes sobre os Termos de apresentação obrigatória:

Termos jả descritos anteriormente.

Recomendações:

Não há.

Conclusões ou Pendências e Lista de Inadequações:

O TCLE foi corrigido e dirigido aos pais ou responsáveis;

O termo paciente foi substituido por participante;

O termo dado foi substituído por dano;

No Termo de Assentimento consta $o$ aceite do adolescente;

O número de participantes foi corrigido no resumo;

Incluiu-se na metodologia a aplicação de laser no pulso;

Removeram da Plataforma Brasil a fase 1.

Diante destas correções todas as pendências foram atendidas.

Consideraçöes Finais a critério do CEP:

$O$ pesquisador deve atentar que o projeto de pesquisa aprovado por este CEP refere-se ao protocolo submetido para avaliação. Portanto, conforme a Resolução CNS 466/12, o pesquisador é responsável por "desenvolver o projeto conforme delineado", se caso houver alterações nesse projeto, este CEP deverá ser comunicado em emenda via Plataforma Brasil, para nova avaliação.

Cabe ao pesquisador notificar via Plataforma Brasil o relatório final para avaliação. Os Termos de Consentimento Livre e Esclarecidos e/ou outros Termos obrigatórios assinados pelos participantes da pesquisa deverão ser entregues ao CEP. Os relatórios semestrais devem ser notificados quando solicitados no parecer.

Este parecer foi elaborado baseado nos documentos abaixo relacionados:

Endereço: Rua Silvio Marchione, 3-20

Bairro: Vila Nova Cidade Universitána

UF: SP

Municipio: BAURU

CEP: $17.012-900$

Telefone: (14)3235-8421

Fax: $(14) 3234-7818$

E-mail: eephraogusp.br 


\section{USP - HOSPITAL DE REABILITAÇÃO DE ANOMALIAS CRANIOFACIAIS}

Contunuaç50 do Parecer. 3.046 .783

\begin{tabular}{|c|c|c|c|c|}
\hline Tipo Documento & Arquivo & Postagem & Autor & Situação \\
\hline $\begin{array}{l}\text { Informações Básicas } \\
\text { do Projeto }\end{array}$ & $\begin{array}{l}\text { PB_INFORMAÇŌES_BASICAS_DO_P } \\
\text { ROJETO_1229221.pdf }\end{array}$ & $\begin{array}{c}19 / 11 / 2018 \\
13: 54: 42\end{array}$ & & Aceito \\
\hline Outros & Carta_Encaminham_Pendencia.pdf & $\begin{array}{c}19 / 11 / 2018 \\
13: 54: 11\end{array}$ & $\begin{array}{l}\text { Pedro Henrique } \\
\text { Hemanes Job }\end{array}$ & Aceito \\
\hline $\begin{array}{l}\text { TCLE / Termos de } \\
\text { Assentimento / } \\
\text { Justificativa de } \\
\text { Ausência }\end{array}$ & Term_Aquiesc_corrigido.docx & $\begin{array}{c}19 / 11 / 2018 \\
13: 50: 50\end{array}$ & $\begin{array}{l}\text { Pedro Henrique } \\
\text { Hemanes Job }\end{array}$ & Aceito \\
\hline $\begin{array}{l}\text { Projeto Detalhado / } \\
\text { Brochura } \\
\text { Investigador }\end{array}$ & Projeto_Pesquisa_corrigido.docx & $\begin{array}{c}19 / 11 / 2018 \\
13: 50: 25\end{array}$ & $\begin{array}{l}\text { Pedro Henrique } \\
\text { Hemanes Job }\end{array}$ & Aceito \\
\hline $\begin{array}{l}\text { TCLE / Termos de } \\
\text { Assentimento / } \\
\text { Justificativa de } \\
\text { Ausência }\end{array}$ & Justif_TCLE_comigido.docx & $\begin{array}{c}19 / 11 / 2018 \\
13: 50: 01\end{array}$ & $\begin{array}{l}\text { Pedro Henrique } \\
\text { Hemanes Job }\end{array}$ & Aceito \\
\hline $\begin{array}{l}\text { TCLE / Termos de } \\
\text { Assentimento / } \\
\text { Justificativa de } \\
\text { Ausência }\end{array}$ & AnaLucia_TCLE.docx & $\begin{array}{c}21 / 10 / 2018 \\
16: 35: 20\end{array}$ & $\begin{array}{l}\text { Renata Paciello } \\
\text { Yamashita }\end{array}$ & Aceito \\
\hline Outros & ChecklistAnaLucia79_2018.docx & $\begin{array}{c}21 / 10 / 2018 \\
15: 46: 03 \\
\end{array}$ & $\begin{array}{l}\text { Renata Paciello } \\
\text { Yamashita }\end{array}$ & Aceito \\
\hline $\begin{array}{l}\text { TCLE / Termos de } \\
\text { Assentimento / } \\
\text { Justificativa de } \\
\text { Ausência }\end{array}$ & Justif_TCLE.docx & $\begin{array}{c}16 / 10 / 2018 \\
14: 12: 43\end{array}$ & $\begin{array}{l}\text { Pedro Henrique } \\
\text { Hemanes Job }\end{array}$ & Aceito \\
\hline $\begin{array}{l}\text { Projeto Detalhado / } \\
\text { Brochura } \\
\text { Investigador }\end{array}$ & Projeto_Pesquisa.docx & $\begin{array}{c}10 / 10 / 2018 \\
10: 53: 27\end{array}$ & $\begin{array}{l}\text { Pedro Henrique } \\
\text { Hemanes Job }\end{array}$ & Aceito \\
\hline Outros & Term_Perm_Uso_Registro.docx & $\begin{array}{c}10 / 10 / 2018 \\
10: 46: 25\end{array}$ & $\begin{array}{l}\text { Pedro Henrique } \\
\text { Hemanes Job }\end{array}$ & Aceito \\
\hline $\begin{array}{l}\text { TCLE / Termos de } \\
\text { Assentimento / } \\
\text { Justificativa de } \\
\text { Ausência }\end{array}$ & Term_Aquiesc.docx & $\begin{array}{c}10 / 10 / 2018 \\
10: 44: 39\end{array}$ & $\begin{array}{l}\text { Pedro Henrique } \\
\text { Hemanes Job }\end{array}$ & Aceito \\
\hline Outros & Carta_Encaminham.pdf & $\begin{array}{c}10 / 10 / 2018 \\
10: 37: 18 \\
\end{array}$ & $\begin{array}{l}\text { Pedro Henrique } \\
\text { Hemanes Job }\end{array}$ & Aceito \\
\hline $\begin{array}{l}\text { Declaração de } \\
\text { Instituição e } \\
\text { Infraestrutura }\end{array}$ & Form_Cadastro_HRAC.pdf & $\begin{array}{c}10 / 10 / 2018 \\
10: 35: 41\end{array}$ & $\begin{array}{l}\text { Pedro Henrique } \\
\text { Hemanes Job }\end{array}$ & Aceito \\
\hline Outros & $\begin{array}{l}\text { Term_Comp_Tornar_Publico_Dest_Mat. } \\
\text { pdf }\end{array}$ & $\begin{array}{c}10 / 10 / 2018 \\
10: 35: 21 \\
\end{array}$ & $\begin{array}{l}\text { Pedro Henrique } \\
\text { Hemanes Job }\end{array}$ & Aceito \\
\hline Outros & Term_Comp_Pesq_Resp.pdf & $\begin{array}{c}10 / 10 / 2018 \\
10: 35: 05\end{array}$ & $\begin{array}{l}\text { Pedro Henrique } \\
\text { Hemanes Job } \\
\end{array}$ & Aceito \\
\hline Folha de Rosto & Folha_Rosto.pdf & $\begin{array}{c}10 / 10 / 2018 \\
10: 27: 48\end{array}$ & $\begin{array}{l}\text { Pedro Henrique } \\
\text { Hemanes Job }\end{array}$ & Aceito \\
\hline
\end{tabular}

Endereço: Rua Silvio Marchione, 3-20

Bairro: Vila Nova Cidade Universitária

UF: SP Municipio: BAURU

Telefone: (14)3235-8421 Fax: (14)3234-7818 E-mail: oephracgusp.br 


\section{USP - HOSPITAL DE \\ REABILITAÇÃO DE \\ Platoformo} ANOMALIAS CRANIOFACIAIS

Conthuaç50 do Parecer. 3.046 .783

Situação do Parecer:

Aprovado

Necessita Apreciação da CONEP:

Não

BAURU, 29 de Novembro de 2018

Assinado por:

Renata Paciello Yamashita

(Coordenador(a))

Endereço: Rua Silvio Marchione, 3-20

Bairro: Vila Nova Cidade Universitária

UF: SP Municipio: BAURU

CEP: $17.012-900$

Telefone: (14)3235-842

Fax: $(14) 3234-7818$

E-mail: oephracgusp.br

Foging ou de os 